\title{
Sparse Coding and Lateral Inhibition Arising from Balanced and Unbalanced Dendrodendritic Excitation and Inhibition
}

\author{
Yuguo Yu, ${ }^{1,2,}$ Michele Migliore, ${ }^{2,3 \star}$ Michael L. Hines, ${ }^{2}$ and Gordon M. Shepherd ${ }^{2}$ \\ ${ }^{1}$ Center for Computational Systems Biology, The State Key Laboratory of Medical Neurobiology and Institutes of Brain Science, Fudan University, School of \\ Life Sciences, Shanghai, 200433, China, ${ }^{2}$ Department of Neurobiology, Yale University School of Medicine, New Haven, Connecticut 06520, and ${ }^{3}$ Institute of \\ Biophysics, National Research Council, 90146 Palermo, Italy
}

\begin{abstract}
The precise mechanism by which synaptic excitation and inhibition interact with each other in odor coding through the unique dendrodendritic synaptic microcircuits present in olfactory bulb is unknown. Here a scaled-up model of the mitral-granule cell network in the rodent olfactory bulb is used to analyze dendrodendritic processing of experimentally determined odor patterns. We found that the interaction between excitation and inhibition is responsible for two fundamental computational mechanisms: (1) a balanced excitation/ inhibition in strongly activated mitral cells, leading to a sparse representation of odorant input, and (2) an unbalanced excitation/ inhibition (inhibition dominated) in surrounding weakly activated mitral cells, leading to lateral inhibition. These results suggest how both mechanisms can carry information about the input patterns, with optimal level of synaptic excitation and inhibition producing the highest level of sparseness and decorrelation in the network response. The results suggest how the learning process, through the emergent development of these mechanisms, can enhance odor representation of olfactory bulb.
\end{abstract}

Key words: balanced excitation/inhibition; dendrodendritic synapse; lateral inhibition; odor coding; olfactory bulb; sparse coding

\section{Introduction}

Lateral inhibition is an essential property in early sensory processing, mediating; for example, contrast enhancement in vision (Kuffler, 1953; Tomita, 1958), tone discrimination in audition (Oswald et al., 2006), and two-point discrimination in somatosensation (Fuchs and Brown, 1984). In the olfactory system there is strong evidence for lateral inhibition between mitral cells in the olfactory bulb, mediated by interactions through dendrodendritic synapses with the inhibitory granule cells(Rall et al., 1966; Rall and Shepherd, 1968; Antón et al., 1993; Davison, Feng et al., 1999; Urban et al., 2000; Margrie et al., 2001; Urban, 2002; Egger et al., 2003; Olsen and Wilson, 2008; Valley and Firestein, 2008; Arevian et al., 2008; Giridhar et al., 2011; Whitesell et al., 2013). Recent studies show that synaptic inhibition plays a critical role in the olfactory bulb for odor discrimination (Abraham et

\footnotetext{
Received May 2, 2014; revised July 23, 2014; accepted Aug. $27,2014$.

Author contributions: Y.Y., M.M., and G.M.S. designed research; Y.Y. and M.L.H. performed research; Y.Y. analyzed data; Y.Y., M.M., and G.M.S. wrote the paper.

This project is funded by the National Natural Science Foundation of China (31271170), the program for Professor of Special Appointment (Eastern Scholar SHH1140004) at Shanghai Institutions of Higher Learning, Grant DC-00086 from the National Institute of Deafness and Other Communication Disorders, and Grant R01DC009977-03 from the National Institute of Deafness and Other Communication Disorders, National Institute of Mental Health, National Institute of Neurological Disorders and Stroke, and National Institute on Aging, and Grant NS11613 from the National Institute of Neurological Disorders and Stroke. We thank Kensaku Mori for providing us with the raw data of glomeruli activation for all odors, and PRACE for awarding us access to 12 Million core-hours on the CINECA IBM BG/Q 163,840-processor system

*Y.Y. and M.M. contributed equally to this work.

The authors declare no competing financial interests.

Correspondence should be addressed to Yuguo Yu, Fudan University, Shanghai, 200433. E-mail: yuyuguo@fudan.edu.cn.

DOI:10.1523/JNEUROSCI.1834-14.2014

Copyright $\odot 2014$ the authors $\quad 0270-6474 / 14 / 3413701-13 \$ 15.00 / 0$
}

al., 2010; Nunez-Parra et al., 2013), and disruption of granule cell inhibition can degrade odor discrimination (Abraham et al., 2010; Nunez-Parra et al., 2013). It was also postulated that this inhibition is involved in generation of oscillatory rhythms (Lagier et al., 2007). Here we analyze how excitation and inhibition in dendrodendritic synapses between mitral cell secondary (lateral) dendrites and granule cell dendrites are coordinated to mediate effective spatiotemporal odor representation.

Odor responses of the mitral cells have been widely examined experimentally (Urban et al., 2000; Lin et al., 2006; Matsumoto et al., 2009) and computationally (Shepherd and Brayton, 1979; Migliore and Shepherd, 2008; Migliore et al., 2010; Koulakov and Rinberg, 2011; Yu et al., 2013), and have been found to be heterogeneous, spatiotemporally sparse, and often precisely timed, in representing the information carried by odor stimuli (Poo and Isaacson, 2009; Khan et al., 2010; Carey and Wachowiak, 2011; Wachowiak, 2011; Shusterman et al., 2011; Smear et al., 2011; Kato et al., 2012). Sparse responses imply that only a small fraction of cells in the network display brief transient responses to input signals (Vinje and Gallant, 2000). This property greatly extends the coding capacity of a large family of sensory inputs (Olshausen and Field, 1996; Dhawale et al., 2010; Wolfe et al., 2010; Koulakov and Rinberg, 2011). Using a highly stylized model, Koulakov and Rinberg (2011) suggested that the possible roles of the dendrodendritic synapses in promoting temporally sparse coding by mitral cells, and computational studies have emphasized that synaptic plasticity during the learning process is a key to transforming the initial intense mitral cell spiking into a subsequent sparse response (Finelli et al., 2008). In addition, it was reported that cell odor responses are more sparse and temporally dynamic in awake compared with anesthetized animals 
(Rinberg et al., 2006). This increased sparseness is believed to reflect increased inhibition through the granule cells (Kato et al., 2012).

Application of experimental techniques to both the level of the reciprocal dendrodendritic synapses and the level of network function to answer these questions is difficult. In contrast to the study of (Koulakov and Rinberg, 2011), we have used a large scale modeling approach based on direct experimental constraints to gain insight into these mechanisms, shifting the focus from the cellular level to the processes within dendrodendritic synapse, and building on our previous study of processing an experimental odor map (Mori et al., 2006) with a scaled-up model of the mitral-granule cell network (Yu et al., 2013). The results show that relatively balanced dendrodendritic excitation and inhibition is critical for the development of a sparse mitral-cell response, whereas unbalanced dendrodendritic excitation and inhibition (inhibition dominated) underlies the development of lateral inhibition. The model suggests that the resulting sparseness and lateral inhibition play critical role in network response decorrelation. The relation of these properties to sparse odor representation, and implications for further experimental tests, are discussed.

\section{Materials and Methods}

Computational simulations. All simulations were performed with the NEURON simulation program (v7.3; Hines and Carnevale, 1997, 2001) on a Cray XE6 system (INCF). The network (Yu et al., 2013) was composed of multicompartment canonical models of 500 mitral and 10,000 granule cells, connected through dendrodendritic synapses (for review, see Shepherd et al., 2007). The model description for active properties, cell morphology, odor inputs, and synaptic connectivity were identical to those used in Yu et al. (2013). The simulation files specifically used to run the simulations described in this work are available from the ModelDB database (http://senselab.med.yale.edu/modeldb, accession number 155720). Kinetic equations and implementation details for all ionic currents can be explored by looking at these model files. Except for run control files, the model is identical to Yu et al. (2013) model accession number 144570. Unless noted otherwise, all simulations were performed for $10 \mathrm{~s}$. For our reader's convenience, in the following paragraph we report again and discuss in more details issues related to the plasticity rule used for all simulations.

Synaptic connectivity and plasticity. The interconnectivity between mitral and granule cells is the critical factor in shaping the network of interactions, and experimental evidence (for review, see Mandairon and Linster, 2009) suggests that the overall effective connectivity is modulated by the past activity of the olfactory bulb. This process presumably builds on an initial configuration of mitral-granule connections formed during development that is unknown. Consistent with experimental estimation of connectivity between pyramidal cells and interneurons in the cortex (Otsuka and Kawaguchi, 2009), in this paper we have used an initial configuration in which each granule cell was randomly connected to $10 \pm 5 \%$ of the mitral cell lateral dendrites directly above it. This should be considered as the maximum average connectivity that can be obtained between any mitral and any granule cells in our network. The effect of different connection probabilities was investigated in a previous paper (Yu et al., 2013, their Fig. 6).

Given the lack of specific experimental information on the processes underlying synaptic plasticity of dendrodendritic synapses in the olfactory bulb, we used a generic use-dependent plasticity rule implemented as follows. All synaptic weights started at zero and, in response to an odor input, each component (inhibitory or excitatory) of each dendrodendritic synapse was independently modified according to the local spiking activity in the lateral dendrite of the mitral cell or in the granule cell synapse. After each spike, the peak conductance $(w)$ and the state $(p)$ of any given synapse were updated from their current value, $w_{\{e x c, i n h\}, p}=$ $g_{\max ,\{e x c, i n h\}} \cdot S(p)$, to a new value calculated according the instantaneous presynaptic interspike interval (ISI) as follows (Migliore et al., 2007, their Fig. 1B,C):

$$
w_{\{e x c, i n h\}, p+\Delta}=g_{\max ,\{e x c, i n h\}} \times S(p+\Delta)
$$

where the function used to update the value of $p$ which was limited to the range $0-50, \Delta=[0,+1,-1]$, followed a classical scheme (Bienenstock et al., 1982; Stanton, 1996) in which $\Delta=0$ for an ISI $\geq 250 \mathrm{~ms}$ (i.e., no changes for a spike frequency $\leq 4 \mathrm{~Hz}$ ), $D=-1$ for $33<$ ISI $<250 \mathrm{~ms}$ (LTD in the range of $4-30 \mathrm{~Hz}$ ), and $\Delta=1$ for ISI $\leq 33 \mathrm{~ms}$ (LTP for a spike frequency $\geq 30 \mathrm{~Hz}) . S(p)$ was implemented as a typical sigmoidal activation function (Haykin, 1994), and defined as $S(p)=1 /\{1+\exp [(25-$ $p) / 3]\}$. In this way, the weight (i.e., the peak synaptic conductance) of any given synapse could go from a fully depressed ( $w \approx 0$, for $p=0$ ) to a fully potentiated state $\left(w \approx g_{\text {max }}\right.$, for $p=50$ ), or vice versa, in 50 consecutive spikes of the appropriate frequency. At the beginning of a simulation $p=$ 0 , and spikes resulting in values of $p<0$ or $p>50$ were ignored.

This plasticity rule is non-Hebbian, because it changes a synaptic weight according to the presynaptic activity, ignoring postsynaptic depolarization. Simulations performed using a Hebbian rule (Migliore et al., 2010) also resulted in network sparseness and the formation of synaptic clusters. Cluster formation independence with respect to these very different learning rules can be understood by considering: (1) a strong odor input causes mitral cells to fire at high-frequency; (2) somatic APs backpropagate along the lateral dendrites and potentiate excitatory mitralgranule synapses along their way, activating granule cells; (3) granule cells begin to fire at high-frequency, potentiating inhibitory synapses on the lateral dendrites of mitral cells, (4) inhibition from granule cells hinders AP back-propagation as it travels far from the soma, thus reducing, locally, the firing frequency of mitral and granule cells, and (5) this finally results in the selective depression of synapses far from the soma of the active mitral cell. Therefore, as long as: (1) action potentials backpropagate along the mitral cell lateral dendrites (Bischofberger and Jonas, 1997; Debarbieux et al., 2003), (2) granule cells form dendrodendritic connections (Rall and Shepherd, 1968), and (3) LTD and LTP are induced by different levels of synaptic activity, the formation of synaptic clusters consistent with those observed experimentally (Willhite et al., 2006) is extremely robust and does not depend on the details or specific choice for the functional form used to update the synaptic weights.

Sparseness calculation. The sparseness of a population code can be quantified (for any given stimulus) as (Vinje and Gallant, 2000; Franco et al., 2007):

$$
\mathrm{S}=\left\{1-\frac{\left[\sum_{i=1}^{N}\left(\frac{r_{i}}{N}\right)\right]^{2}}{\sum_{i=1}^{N} \frac{r_{i}^{2}}{N}}\right\} /\left(1-\frac{1}{N}\right),
$$

where $r_{i}$ is the mean firing rate of neuron $i$ in a set of $N$ neurons. This is a measure of the extent of the tail of the distribution, in this case of the firing rates of a population of neurons to a stimulus. Values of $S$ near $0 \%$ indicate a dense code, and values near $100 \%$ indicate a sparse code $(\mathrm{Ol}-$ shausen and Field, 1996). A high value indicates that there is a long tail to the distribution, equivalent in this case to only a few neurons with high firing rates.

Correlation coefficient. To calculate the correlation coefficient of neuronal firing in a network, we use a coherence measure based on the normalized cross-correlation of neuronal pairs in the network. The coherence between two neurons $i$ and $j$ is measured by their crosscorrelation of spike trains at zero time lag within a time bin of $\tau$. Precisely, supposing that a long time interval $T$ is divided into small bins of $\tau$, and that two spike trains are given by $X(l)=0$ or $1, Y(l)=0$ or 1 , with $l=$ $1,2, . ., K$ (here $T / K=\tau$ ), respectively, a coherence measure for the pair is then defined as follows (Wang and Buzsáki, 1996):

$$
K_{i j}(\tau)=\frac{\sum_{l=1}^{N} X(l) Y(l)}{\sqrt{\sum_{l=1}^{N} X(l) \sqrt{\sum_{l=1}^{N} Y(l)}} .}
$$


A

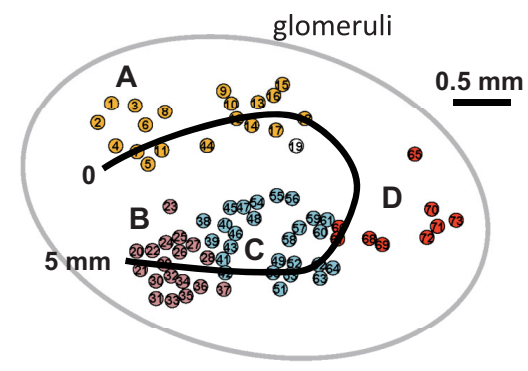

Olfactory Bulb circuit
B

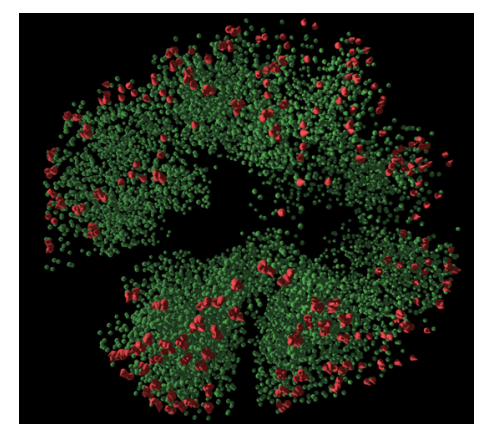

MT-GC circuit network
C

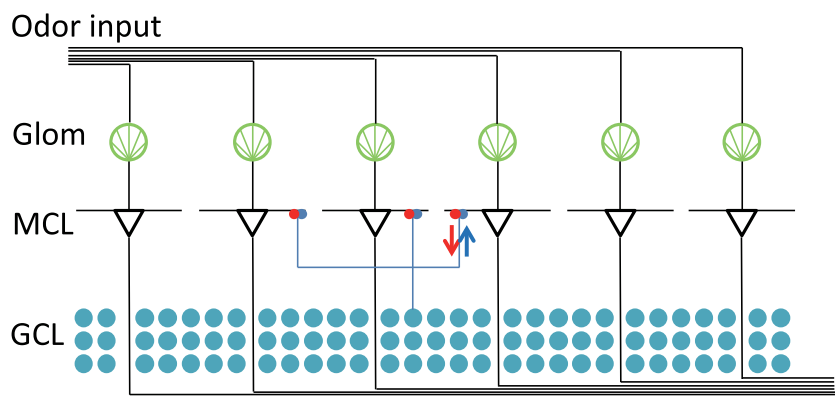

Odor input

MT-GC network configration

Figure 1. Schematic description of the model and its relation to in vivo experimental data. $A$, Spatial distribution of the 73 glomeruli activated by the 72 odors used in this work. The 73 glomeruli constitute the input layer to the MC Circuitry. $B$, A plot of 3-D representation of the mitral and granule cells within the bulb model. The MCs (total number 500 ) are indicated by the red pyramids, whereas $\mathrm{GCS}$ (total number 10,000) are indicated by the small green spheres. C, The feedback and feedforward connectivity among the MCs and GCs in the OB model. MCs (triangles) receive excitatory inputs from glomeruli (large green circles). The MCs and GCs (solid blue circles) are connected by reciprocal dendrodendritic synapses; one GC connection is shown as an example. The GCS receive the excitatory inputs from the MCs (red arrow), and MCs are inhibited by GCS (blue arrow). $\boldsymbol{D}$, Reciprocal synapses mediate interactions between mitral cells and granule cells in the OB (see text). $\boldsymbol{A}$ and $\boldsymbol{B}$ were taken from Yu et al. (2013).

Furthermore, a population coherence measure $k$ is defined by the average of $k_{i j}($ [GRAPHIC] $)$ over all pairs of neurons in the network, that is

$$
K=\frac{1}{N(N-1)} \sum_{i=1}^{N} \sum_{j=1, j \neq i}^{N} K_{i j}(\tau) .
$$

Thus, $k$ is used to quantify the correlation level of network spiking patterns within a certain time window in the network. In this paper, we take $\tau$ as $20 \mathrm{~ms}$ through the whole analysis.

\section{Results}

The glomerular responses to a battery of 72 odor molecules in several homologous chemical series were mapped by recent experiments (Mori et al., 2006). In confirmation of earlier studies (Stewart et al., 1979), they found that a given odor molecule tended to elicit glomerular responses within a given broad area of the olfactory bulb. Within a homologous series, the activated areas were overlapping, referred to collectively as a "domain". Four of these domains were the focus of our study. Glomeruli in domain A responded to aliphatic acids and aliphatic aldehydes; domain $\mathrm{B}$ to aliphatic alcohols; domain $\mathrm{C}$ to members of the phenol family; and domain D to a variety of ketones (Fig. 1A).

The microcircuit model simulating the olfactory bulb network circuitry to examine the odor processing mechanism of these 72 odor input was described in Yu et al. (2013). It consists of a large scale Hodgkin-Huxley neuronal type of biophysical net- work, composed of 500 mitral cells and 10,000 granule cells (Fig. 1B). Each mitral cell model had 20 apical tuft dendritic branches (receiving synaptic inputs from glomerulus) and two lateral dendrites, each with a total length of $1.5 \mathrm{~mm}$. There were $\sim 1000$ dendrodendritic synapses randomly distributed on each lateral dendrite making contacts with granule cells (Fig. 1C). The detailed model parameters are chosen to mimic closely the real mammalian olfactory bulb neuronal properties (Bischofberger and Jonas, 1997; Migliore et al., 1999; Shepherd et al., 2007; Migliore and Shepherd, 2008; Fantana et al., 2008), as described in our previous work (Yu et al., 2013). The organization of the dendrodendritic synapses is indicated in the diagram of Figure $1 D$. Glutamate released from mitral cell (MC) dendrites acts on excitatory receptors in postsynaptic granule cells and causes excitation of granule cell (GC) spines, which trigger GABA release back onto MCs. Near the soma this mediates feedback inhibition; through backpropagating action potentials in the lateral dendrites it mediates lateral inhibition.

The dendrodendritic synaptic connectivity between mitral and granule cells is the critical factor dominating the network dynamics (Rall et al., 1966; Rall and Shepherd, 1968; Isaacson and Vitten, 2003). The focus of the current study is how dendrodendritic interactions result in olfactory network response sparseness and lateral inhibition to produce effective odor representation. Synaptic interactions and processing at the glomerular level, such as that modulated by periglomerular cells (Murphy et al., 2005; Cleland and Linster, 2012; Whitesell et al., 2013), was not explicitly included in this model. However, they are qualitatively taken into account by the input data, which partially reflect these interactions. We plan to include a realistic implementation of interglomerular mechanisms in future studies. We stress that the qualitative aspects of the network self-organization discussed in this paper do not depend on the type of synaptic plasticity implemented in the model. The plasticity rule used here (see Materials and Methods) has been presented, discussed, and validated in our previous work (Migliore et al., 2007; Yu et al., 2013). Also, note that the time scale for the learning process just reflects the simulation time allowing the synaptic weights to reach an equilibrium condition. We have previously reported and discussed (Migliore et al., 2007, 2010) that the results using this rule are robust and do not depend on the specific choice for the functional form or time frame used to update the synaptic weights.

We first examined how the structure of mitral and granule cell spiking and the production of lateral inhibition evolve during the time course of odor learning. Raster plots (Fig. 2A) show the MC and GC responses during a simulation with the odor molecule $o$-ethyl phenol. Mitral cells receiving strong glomerular input respond with a high-frequency discharge during the initial part of the simulation, and then change to intermittent bursting. These strongly activated mitral cells are classified as MC I (Fig. 2, red) in 

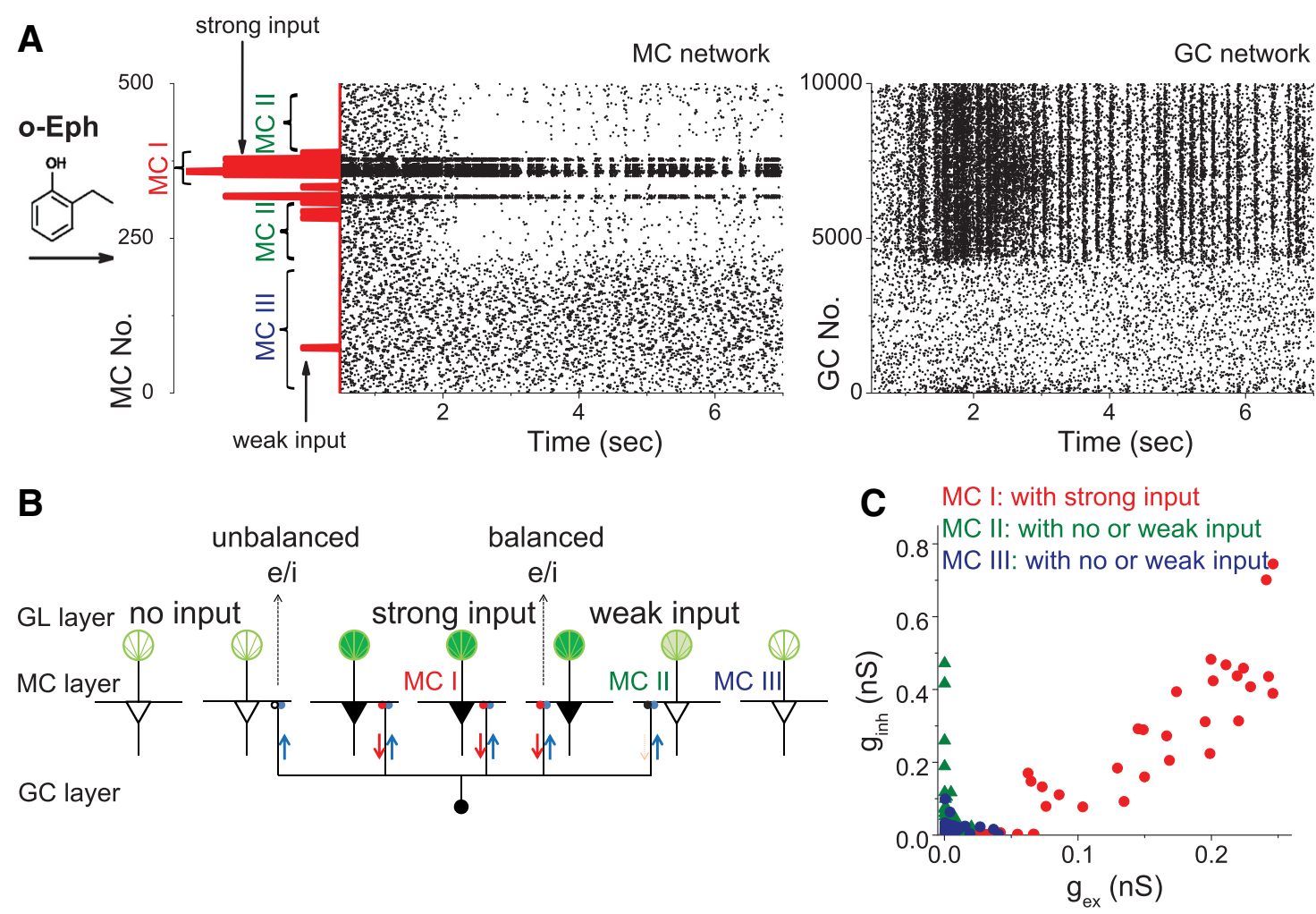

Figure 2. Relation of the model to development of lateral inhibition. $\boldsymbol{A}$, Raster plots of the $500 \mathrm{MCs}$ and the $10,000 \mathrm{GCS}$ connected to those MCs during presentation of the odorant 0 -ethyl phenol (o-Eph); the red histogram represents the intensity of the synaptic input from glomeruli to MCs. $\boldsymbol{B}$, Schematic representation of balanced and unbalanced excitation and inhibition (inhibition dominated) in the MC-GC circuit. Three activated middle MCs (solid black triangles) receive strong input from glomeruli (solid deep green color); through back-propagating APs in their lateral dendrites, they distribute excitation (red) through the reciprocal synapses, activating lateral inhibition to the surrounding MCs through the reciprocal inhibitory synapses. This mode of excitation and inhibition is balanced, and these MCs are called MC type I. The activated GCs (small blue spheres) deliver lateral inhibition to other surrounding MCs with weak or no excitatory inputs, making their reciprocal synapses unbalanced. These MCs are called MC type II. MCs that do not receive lateral inhibition are MC type III (see text). C, Analysis of the 0B model with 72 odorant inputs: the average values of the excitatory and inhibitory weights of the reciprocal synapses are plotted against each other for reciprocal synapses in strongly activated MCI (red); weakly activated and laterally inhibited MC II (green), and distant MC III (blue) beyond lateral inhibition.

this study. Strong lateral inhibition of surrounding mitral cells with weak input (classified as MC II; Fig. 2, green) is observed after the granule cells begin to generate inhibitory signals in response to inputs from MC I ( $\sim t=2 \mathrm{~s}$ in this case). Other MCs outside the range of the lateral dendrites of the strongly activated mitral cells, and thus outside the associated lateral inhibitory action of their activated GCs, are termed MC III (Fig. 2A, blue). GC activation produces continuously high-frequency spiking at the beginning of the simulation (during the early phase of the network self-organization), and later changes to intermittent bursting (Fig. $2 \mathrm{~A}$, right; $\sim t=3 \mathrm{~s}$ ). Intermittent bursting will be referred to as a sparsening of the responses. The sparsened MC bursting and surrounding inhibitory activity reflect the development of intense activation of the granule cell population at the site of the strongly activated MCs (Fig. 2A, right).

The postulated microcircuit for these responses is diagramed in Figure 2B. Following the convention introduced by recent experiments (Shu et al., 2003; Haider et al., 2006) in their study of cortical dynamics involving interactions through interneurons by conventional axo-dendritic and axo-somatic synapses, we characterize the synaptic weights of the dendrodendritic synaptic interactions as "balanced" or "unbalanced". At the site of activated MC I cells, excitation and feedback inhibition are both strong (Fig. $2 B$ ), and the weights are relatively balanced. Because of weak or no excitation, MC II cannot excite the connected granule cells, but they are within the range of the strong surrounding lateral inhibition generated by MC I; their synaptic weights are thus unbalanced, with a strong inhibition and a weak excitation in the dendrodendritic synapse. The synaptic weights of MC III are not relevant for the network operation, because they are weakly or not activated and outside the range of the lateral dendrites of the strongly activated MC I. The inhibitory versus excitatory synaptic weights for reciprocal synapses in the three types of MCs for a network trained with 72 odors is plotted in Figure $2 C$, using the same color code. For reciprocal synapses of MC I, the average ( \pm SEM) synaptic weights for excitation and inhibition are approximately proportional to each other, with a ratio of $g_{\text {inh }} / g_{\text {ex }}=1.24 \pm 0.94$, resulting in a relatively balanced excitation and inhibition. The synaptic weights in MC II are, on average, much stronger for inhibition than for excitation $\left(g_{\text {inh }} /\right.$ $\left.g_{\text {ex }}=529 \pm 227\right)$, resulting in an unbalanced excitation and inhibition (inhibition dominated) associated with lateral inhibition. For synapses of MC III, the synaptic weights for both inhibition and excitation are, in most cases, very low and practically ineffective for network operations because they are not significantly activated by inputs $\left(g_{\mathrm{inh}} / g_{\mathrm{ex}}=24.8 \pm 8.5\right)$. The synaptic weight configurations after a given learning phase depend on the preset values for the peak conductance $g_{\text {inh }}^{\text {Max }}$ and $g_{\text {ex }}^{\text {Max }}$. In Fig. 3 we show the relation between the final synaptic weights after learning and different preset peak conductance. For a fixed excitatory peak conductance $g_{\mathrm{ex}}^{\mathrm{Max}}$, the synaptic inhibitory weight $g_{\text {inh }}$ increased gradually with an increase of peak inhibitory peak conductance $g_{\text {inh }}^{\mathrm{Max}}$ (Fig. 3A), whereas the excitatory weight $g_{\text {ex }}$ decreased (Fig. 3B). For a fixed inhibitory peak conductance $g_{\text {inh }}^{\mathrm{Max}}$, the inhibitory weight $g_{\text {inh }}$ 

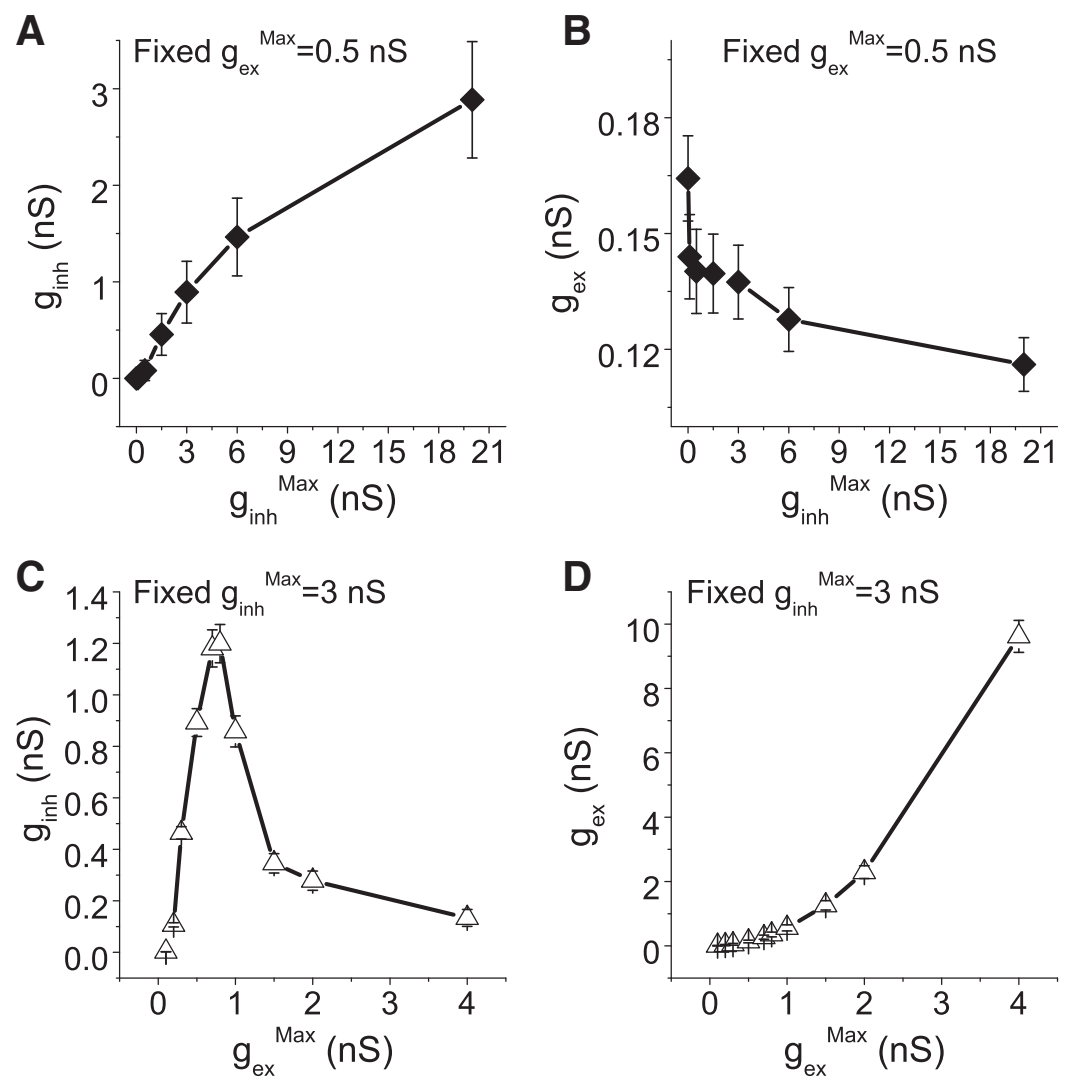

Figure 3. Relationship between the preset synaptic peak conductance and actual synaptic weight. $\boldsymbol{A}$, averaged inhibitory synaptic weight $g_{\text {inh }}$ versus preset inhibitory peak conductance $g_{\text {inh }}^{\text {Max }}$ for a fixed excitatory peak conductance ( $g_{\mathrm{ex}}^{\mathrm{Max}}=0.5 \mathrm{nS}$ ). B, averaged excitatory synaptic weight $g_{\mathrm{ex}}$ versus preset inhibitory peak conductance $g_{\mathrm{inh}}^{\mathrm{Max}}$ for a fixed excitatory peak conductance ( $g_{\mathrm{ex}}^{\mathrm{Max}}=0.5 \mathrm{nS}$ ). C, averaged inhibitory synaptic weight $g_{\text {inh }}$ versus preset excitatory peak conductance $g_{\mathrm{ex}}^{\mathrm{Max}}$ for a fixed inhibitory peak conductance ( $g_{\mathrm{inh}}^{\mathrm{Max}}=3 \mathrm{nS}$ ). . , averaged excitatory synaptic weight $g_{\mathrm{ex}}$ versus preset excitatory peak conductance $g_{\mathrm{ex}}^{\mathrm{Max}}$ for a fixed inhibitory peak conductance ( $g_{\text {inh }}^{\operatorname{Max}}=3 \mathrm{nS}$ ).

first increased and then decreased to a small value as the excitatory peak conductance $g_{\mathrm{ex}}^{\mathrm{Max}}$ increased (Fig. $3 C$ ), whereas the excitatory weight $g_{\text {ex }}$ gradually increased (Fig. $3 D$ ).

The map of the glomerular representation of the odor molecule $o$-ethyl phenol represented by the spatial firing pattern of the mitral cell network at the beginning of the learning phase is shown in Figure $4 A$. The network response reflects detailed features from weak to strong components. Although granule cells from 4200 to 10,000 are strongly activated by the synaptic excitation from activated mitral cells, the mitral cell network is little affected by synaptic inhibition from the granule cell network because the synaptic inhibitory weights are relatively weak at the beginning of the learning. In comparison, Figure $4 B$ shows the network response at the end of the simulation, after the learning process (after $10 \mathrm{~s}$, in this case). There are several notable observations: first, the responses of those mitral cells receiving strong inputs decrease $33 \pm 12 \%$ compared with the responses in the first seconds due to the strong feedback inhibition. Second, the responses to the weak input (indicated by the purple arrows) decrease to almost zero because of the strong lateral inhibition. Third, the surrounding mitral cells without direct inputs show a reduced spontaneous activity, because of the lateral inhibition from the feedforward synaptic inputs from the activated granule cell network (Fig. 4B, bottom).

These results suggest that both the lateral and feedback inhibition are the mechanisms through which the mitral-granule cell circuit enhances the network response to the preferred compo- nents of an odor, while reducing the response to the weak components to increase the contrast between them.

An essential function of processing odor inputs is to efficiently represent odors with similar and dissimilar odor molecule structures. We examined responses of the mitral cell network to odor molecules with structures that were either similar (Fig. 5A-C) or distinctly different (Fig. 5D-F), before (in the first second) and after learning process (in the 10th second, in this case). Notably, before the learning process, the responses of the mitral cells without direct input have similar spontaneous response properties. After the learning process, the responses of the MCs without direct input showed distinct firing patterns because of different lateral inhibition. The mitral cell responses to odor molecules with similar structures also showed distinct spatial firing patterns, with different firing intensities, accurately reflecting the different glomerular input patterns. As was observed in Figure 4, those MCs receiving strong inputs show strong responses, whereas those surrounding with weak inputs showed suppressed responses (Fig. 5, purple arrows). Clearly, lateral inhibition from the granule cell network (Fig. 5A-C, bottom) modulates the spatial firing patterns of the MC network. This is a powerful mechanism for efficiently enhancing odor representation of input odors, and it will be quantified below.

For odor inputs with distinctly different molecular structures, both the mitral and granule cell networks also display distinctly different spatial firing patterns (Fig. $5 D-F$ ). The stronger the input, the stronger is the lateral inhibition of surrounding mitral cells (Fig. 5D,E). For the odor with all weakly responding components (Fig. $5 F$ ), the GC network responses were very low (data not shown), close to the spontaneous activity level. There was little lateral and feedback inhibition to the MC network; in the absence of inhibition, the network showed dense responses to the stimulus features.

Although the odor molecule $8 \mathrm{OH}$ (aliphatic alcohol; Figure $5 C$ ) has a different molecular structure from K7-1 (aliphatic ketone, their long-chain structure has some similarity; Figure 5D), the glomerular activation patterns show similar spatial response features (with correlation coefficient $\sim 0.91$ ), with the two odors activating almost the same group of glomeruli in domain $\mathrm{B}$, and both having similar sweet fruity smells. However, despite the apparent similarity of the mitral cells firing rate in the two cases (Fig. 5C,D), their correlation coefficient was reduced greatly by $64 \%$ after learning (correlation coefficient is decreased from 0.459 to 0.167 ). These results suggest that the network is able to enhance odor representation even in these extreme cases.

Recent experimental findings (Kato et al., 2012) indicated that the network response sparseness increases when the network inhibition level is increased. To examine systematically how the changes of network inhibition modulate the network response sparseness level, and how the balance of inhibitory and excitation 

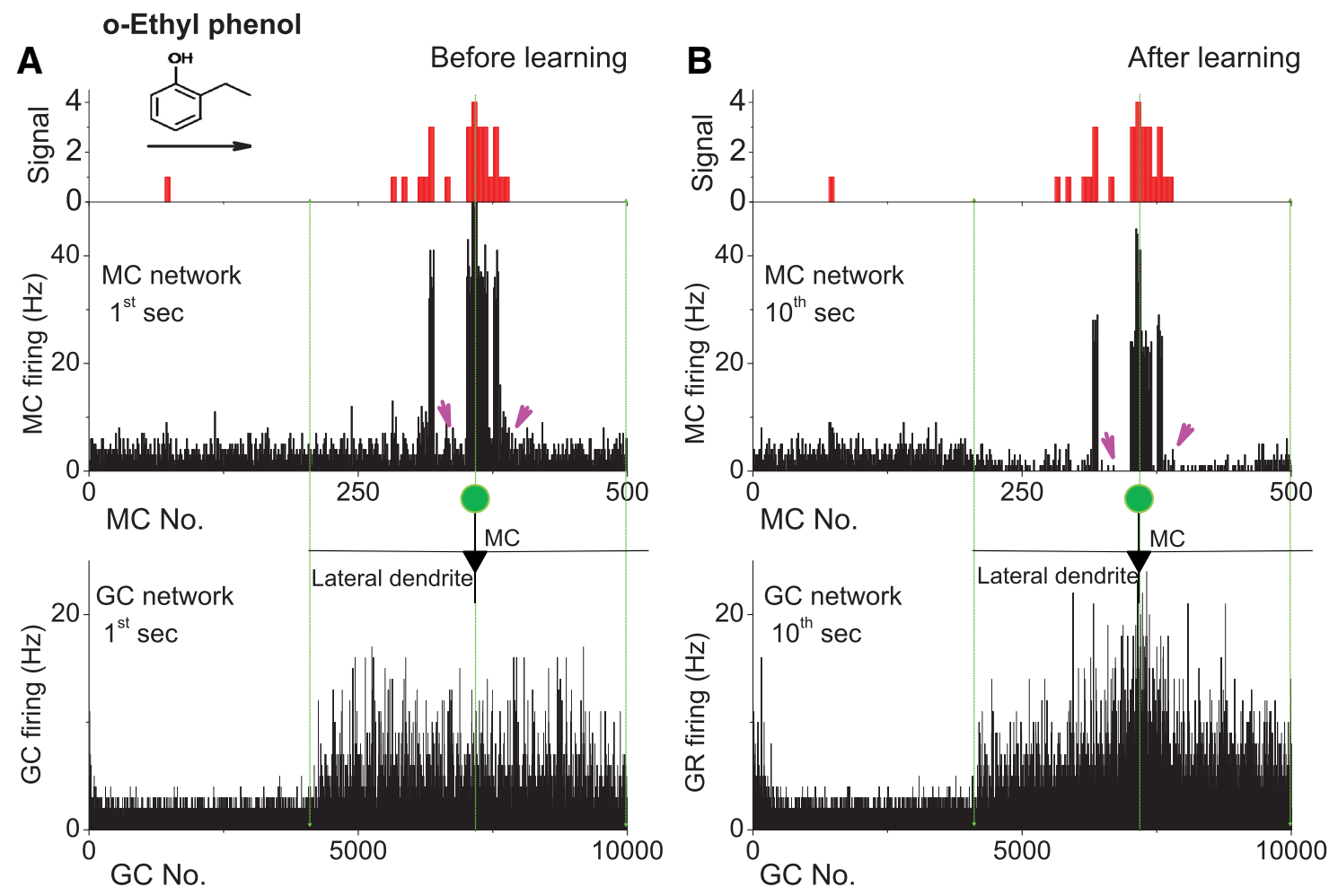

Figure 4. The spatial firing rate pattern of $500 \mathrm{MCs}$ in response to 0 -ethyl phenol. $\boldsymbol{A}$, Patterns in the first seconds of odor exposure, before learning. MCs nos.356-360 have firing rates $\sim 40-50$ $\mathrm{Hz}$ in response to the stronger inputs, whereas surrounding MCs, with weaker input signals, have much lower firing rates (purple arrows). Correspondingly, the MCs receiving weak input that are away from the strongly activated MCs also show relatively low firing rates (blue arrow), which are almost as low as the spontaneous firing rate ( $\sim 4 \mathrm{~Hz}$ ) of MCs with no input. The bottom panel shows the spatial firing rate pattern of $10,000 \mathrm{GCS}$. MCs nos.356 -360 have long lateral dendrites that cover the lateral connection to the GCs within no.4120 - 10,000, and some within no.0 - 20. A model MT cell is plotted in inverted black triangle, with lateral dendrite covered the range of $\mathrm{GCs}$ from $\sim 415$ to 10,000 , and the glomerulus plotted in green circle was activated by the input odor. $\boldsymbol{B}$, Patterns in the 10th seconds, after learning. The strongly activated MCs have reduced the firing rates for strong inputs because of the lateral inhibition, while surrounding MCs nos. $210-500$ are strongly suppressed by the lateral inhibition. Some MCs with weak inputs within this range even stop firing (purple arrows) because of the strong lateral inhibition effect. However, MCs with weak inputs out of this range display relatively enhanced responses (blue arrow) because of very weak feedback inhibition and no lateral inhibition. The GC displays a decreasing pattern of activity in the region surrounding the site where MCs are strongly activated.

level limit the development of MC network response sparseness, we performed a series of simulation experiments.

To investigate how the transient response triggered by each sniff-cycle becomes sparse during the learning process, we chose a relatively low sniff frequency of $2-4 \mathrm{~Hz}$ (Figs. 2-5, compare 1-8 $\mathrm{Hz})$. A raster plot of the mitral and granule cell network responses to an input octanal is shown in Figure 6A. During each sniff cycle, odor-evoked transient responses in the mitral cell-odor pair network (for MCs directly receiving odor inputs) were dense at the beginning before learning (Fig. $6 A, B$ ), then gradually decreased in response intensity and duration for each sniff cycle during the learning process. Finally, the response of the MC odor-pair network in this example (MC no. 400-500) became spatially and temporally sparse (Fig. 6 B, for comparison). Not only the transient response intensity decreased, but also the average time to peak of the response significantly decreased, from 0.072 to 0.031 $\mathrm{s}$ (Fig. $6 B$ ). The response patterns suggest that this was caused by the action of the GC network on the weakly activated mitral cells, which generate spikes with longer latency that are progressively suppressed, as the odor is learned (Fig. $6 \mathrm{~B}$, right; the mitral cell network transient response during a sniff cycle in the last seconds).

We then quantified the mitral cell network population sparseness based on previous reports (Vinje and Gallant, 2000; Franco et al., 2007; see Materials and Methods). Figure $6 \mathrm{C}$ shows that mitral cell network sparseness increased nonlinearly with a sigmoid-like function versus time, and finally reached a relatively saturated level close to 0.9 (the larger the value, the more sparse it is) for given values of excitatory and inhibitory peak conductances $\left(g_{\mathrm{ex}}^{\operatorname{Max}}=0.5, g_{\mathrm{inh}}^{\mathrm{Max}}=3 \mathrm{nS}\right.$, respectively).

The change of the mitral cell network sparseness was accompanied by plasticity changes in the actual synaptic weight of both excitatory and inhibitory reciprocal synapses. Figure $6 D$ shows that the average excitatory synaptic weight for the strong input increased rapidly with time and reached a saturated level $\sim 5 \mathrm{~s}$, whereas the weight for the weak input rose slightly to a small value. Correspondingly, the average inhibitory synaptic weight also increased rapidly for those reciprocal synapses connected to the mitral cells receiving direct strong input. As expected, for the granule cells surrounding strongly activated mitral cells, their inhibitory synapses were activated by the neighboring reciprocal synapses receiving strong excitatory input, and also developed a relatively strong inhibitory synaptic weight (Fig. 6E). These inhibitory synapses send lateral inhibition to the mitral cells receiving weak or no input from glomeruli. Figure $6 F$ shows a plot for the average inhibitory versus excitatory weights for the reciprocal synapses corresponding to the group of mitral cells with strong input or weak input. Clearly, reciprocal synapses on the mitral cells with strong inputs finally reached a relatively balanced excitatory to inhibitory ratio $\sim 3: 1$ (varied from 1:1 to 3:1 depending on odor). For those reciprocal synapses on mitral cells with weak inputs, the inhibitory weight was much higher $(\sim 100$ times higher) than the excitatory weight, resulting in unbalanced excitation and inhibition (inhibition dominated). As discussed for 
A $60 \mathrm{H}$ (Hexanol)
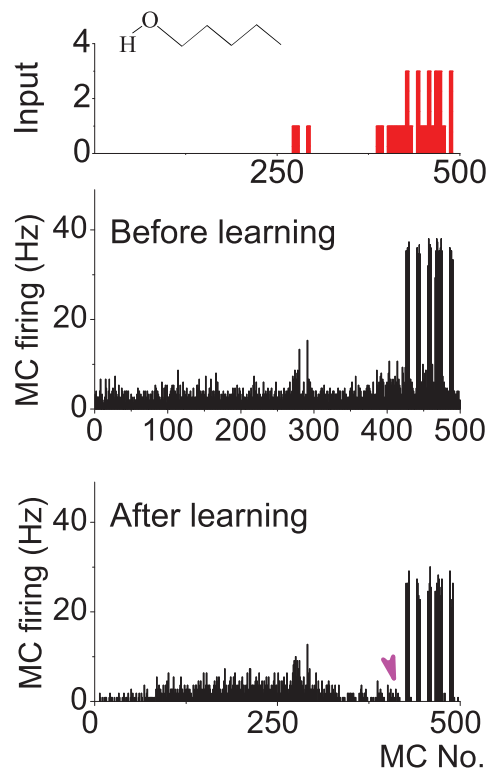

D $\quad \mathbf{k}$-1 (n-Heptyl methyl ketone)
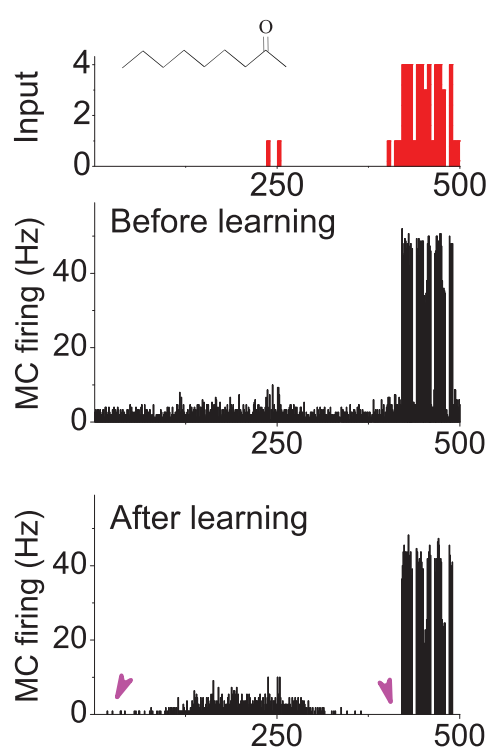

B
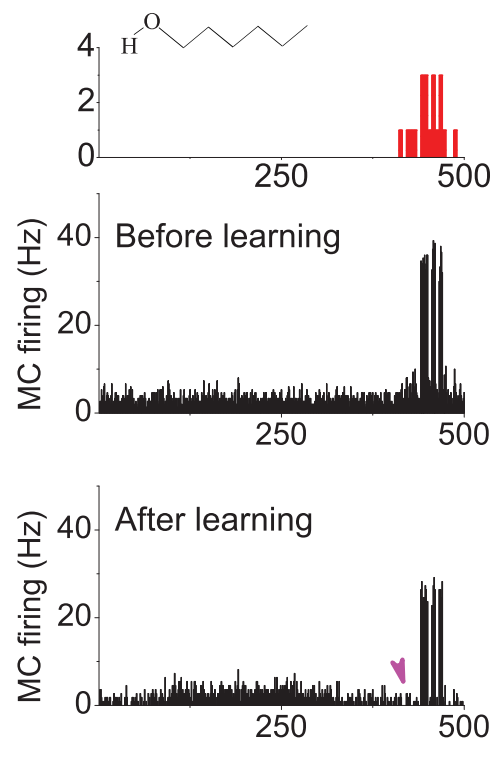

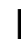
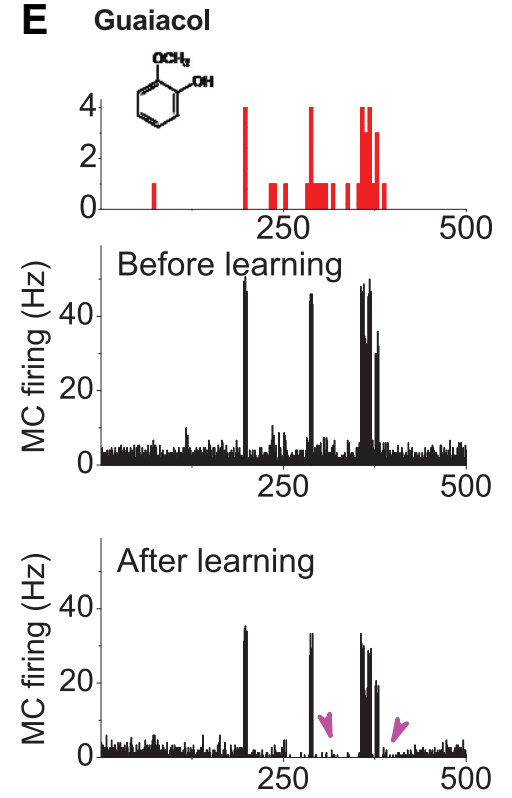

\section{C $80 \mathrm{OH}$ (Octanol)}
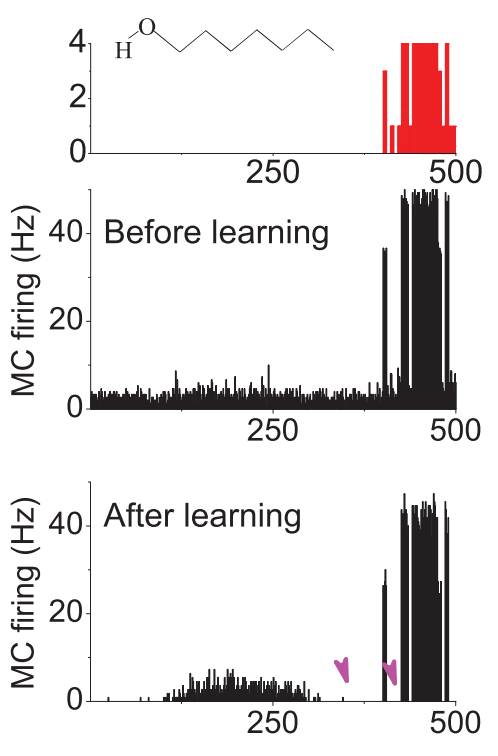

F Piperitone
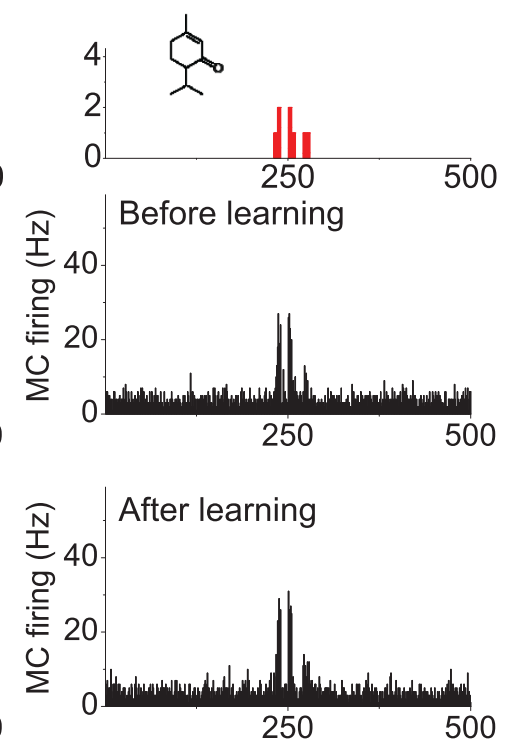

Figure 5. Network processing properties. The spatial firing rate pattern of $500 \mathrm{MCs}$ in response to odors with similar $(\boldsymbol{A}-\boldsymbol{C})$ and different $(\boldsymbol{D}-\boldsymbol{F})$ molecular structures before (top) and after (bottom) the learning process. The odors are $60 \mathrm{H}$ for $\boldsymbol{A}, 70 \mathrm{H}$ for $\boldsymbol{B}, 80 \mathrm{H}$ for $\boldsymbol{C}, \mathrm{K} 7-1$ for $\boldsymbol{D}$, guaiacol for $\boldsymbol{E}$, and piperitone for $\boldsymbol{F}$. Purple arrows indicate $\mathrm{MC}$ s with a response strongly affected by lateral inhibition.

Figure $2 C$, the unbalanced excitation/inhibition (inhibition dominated) is associated with the emergence of lateral inhibition, whereas the balanced excitation/inhibition appears related to the sparse mitral cell network response in representing the input odors.

Recent studies have reported that higher levels of synaptic inhibition can give a sparser sensory response (Poo and Isaacson, 2009; Kato et al., 2012). We therefore varied the value of the synaptic peak conductance for both excitatory and inhibitory synapses, and accordingly the excitatory/inhibitory balance, to examine this issue in the mitral-granule cell network.

We first showed that, with a fixed excitatory synaptic peak conductance, $g_{\mathrm{ex}}^{\mathrm{Max}}=0.5 \mathrm{nS}$, the network response to a given odor input evolved over time to reach different sparseness levels for different values of the inhibitory synaptic peak conductance $g_{\text {inh }}^{\mathrm{Max}}$.
For $g_{\text {inh }}^{\mathrm{Max}}=0$, the mitral cell network maintained a dense response and accordingly low sparseness (Fig. 7A, dark color line). When $g_{\text {inh }}^{\mathrm{Max}}$ was increased to $0.1 \mathrm{nS}$, the sparseness increased slowly (see blue color line). The highest sparseness occurred with $g_{\text {inh }}^{\mathrm{Max}}=3$. When $g_{\text {inh }}^{\mathrm{Max}}$ was increased to an even larger value of $20 \mathrm{nS}$, the network sparseness arose earlier, but the saturated sparseness level was lower. This result suggests that there is an optimal synaptic inhibition level for which the neuronal network can develop the highest level of response sparseness (Fig. $7 B, C$ ).

The fact that a further increase of inhibition did not further increase sparseness can be understood by considering that mitral cells receiving a stronger inhibition reduce their firing rate. The relatively low firing rates of mitral cells have two effects: (1) a lower excitation of connected granule cells, leading to a lower 
level of lateral inhibition on the surrounding mitral cells, which would thus be more active (Fig. $7 D-G$ ), (2) the average synaptic excitatory weight from MCs toGCs decreases as the inhibitory conductance increases (Fig. 3B). This results in a decrease of firing rate in connected granule cells, and finally leads to a lower inhibition. The overall effect of a large peak inhibitory synaptic conductance is thus to reduce the sparseness level of the mitral cell network.

Moreover, the same type of results were obtained by fixing the inhibitory peak conductance to be $3 \mathrm{nS}$, while changing excitatory synaptic peak conductance from 0 to $4 \mathrm{nS}$ (Fig. 3C,D). In this case, we found that the overall network sparseness level could be maximized by an optimal excitatory synaptic peak conductance $\sim 0.5-$ $0.7 \mathrm{nS}$ (data not shown). Either a small or a large excitation leads to a final low level of synaptic inhibition (Fig. 3C), which results in a dense mitral network activity.

Sparse coding has been proposed as an efficient scheme by which each individual neuron independently encodes different aspects of the input stimulus (Olshausen and Field, 1996; Vinje and Gallant, 2000). If this is correct, we should predict lower correlated responses among neurons within the network for a situation in which the mitral cell network reaches a higher sparseness level. We measured the correlation level of the MT network response (see Materials and Methods) by first calculating the correlation coefficient of each pair of mitral cell responses $\mathrm{MC}_{i}(t)$ and $\mathrm{MC}_{j}(t)$ within all 500 mitral cells, and then averaging the correlation coefficient of all the pairs of mitral cells in the network for each given condition discussed in Figures 7 and 3. The results are plotted in Figure $8 A, B$. For $g_{\mathrm{ex}}^{\mathrm{Max}}=0.5 \mathrm{nS}$, the average MC network correlation coefficient gradually decreased with time to a lower level for different values of $g_{\text {inh }}^{\mathrm{Max}}\left(\right.$ except for $g_{\text {inh }}^{\mathrm{Max}}=$ $0 \mathrm{nS}$ ). For the optimal $g_{\text {inh }}^{\mathrm{Max}}=3 \mathrm{nS}$, the correlation level of the network reached the lowest value (Fig. $8 A, C$ ). Similarly, for a fixed $g_{\text {inh }}^{\mathrm{Max}}=3 \mathrm{nS}$, the network correlation levels evolved with time to lower values for different values of $g_{\mathrm{ex}}^{\text {Max }}$; there exists an optimal $g_{\mathrm{ex}}^{\mathrm{Max}}$ where the network response reaches the lowest correlation level (Fig. $8 B, C)$. Figure $8 D$ summarizes the above results, and shows that the mitral cell network correlation level is negatively proportional to the mitral cell sparseness level.

To investigate whether there is a dominant factor leading to network sparseness, we plotted the sparseness as a function of the ratio of synaptic weight $g_{\text {inh }}^{\mathrm{Max}} / g_{\mathrm{ex}}^{\mathrm{Max}}$ (Fig. $8 E$; for all the conditions listed in Fig. 7). Whether changing the value of $g_{\text {inh }}^{\mathrm{Max}}$ for a fixed $g_{\mathrm{ex}}^{\operatorname{Max}}$, or $g_{\mathrm{ex}}^{\operatorname{Max}}$ for a fixed $g_{\text {inh }}^{\operatorname{Max}}$, the network sparseness levels for all these conditions strictly followed the ratio of $g_{\text {inh }}^{\mathrm{Max}} / g_{\mathrm{ex}}^{\mathrm{Max}}$. We conor weak (black) inputs.
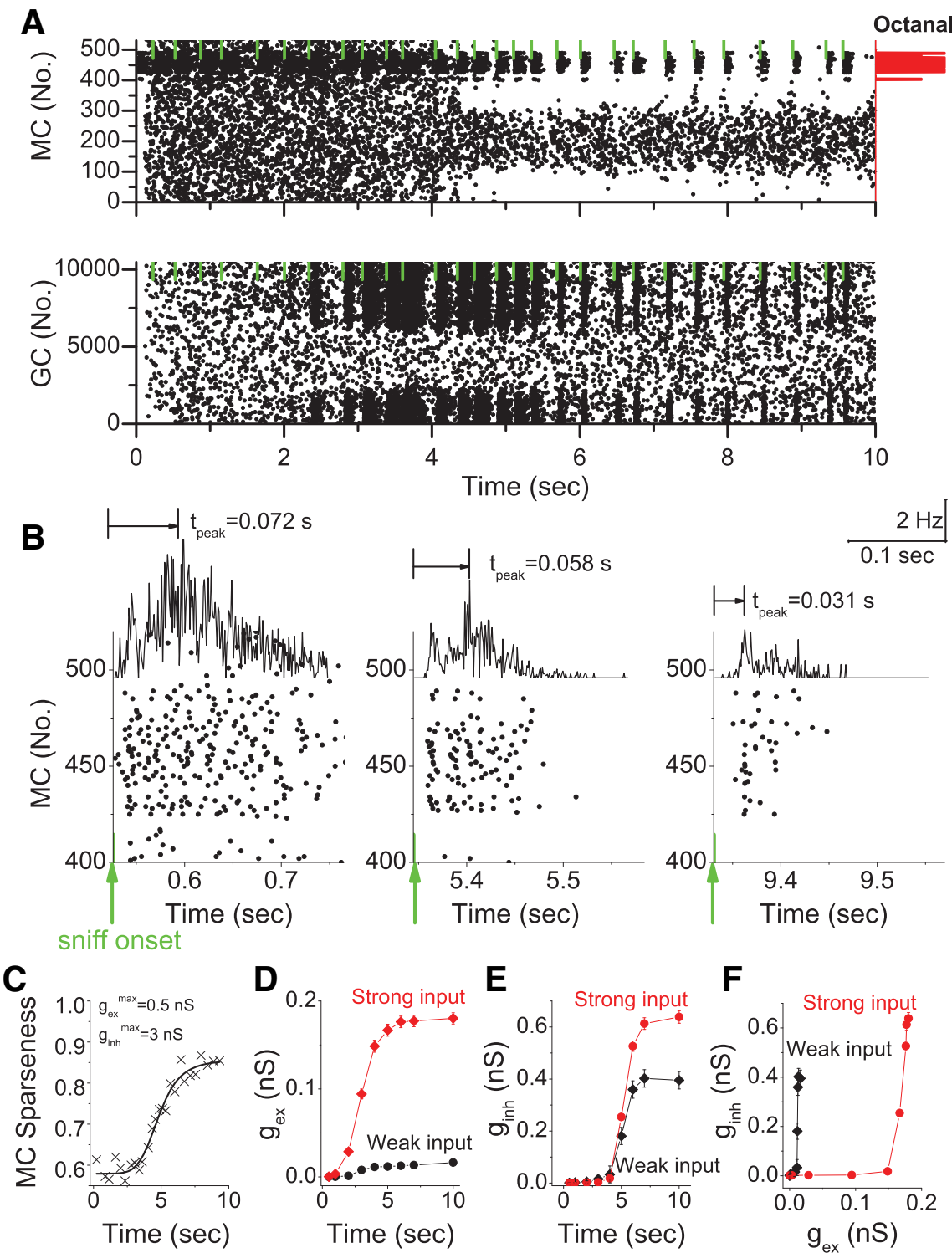

Figure 6. The response dynamics of the MCs develops from intense to sparse. $\boldsymbol{A}$, Raster plot of spike timings from MC (top) and GC (bottom) during a typical simulation; MC spiking evolved from intense to sparse as a function of time in response to the odor octanal (sniff frequency was randomly set in a range from 2 to $5 \mathrm{~Hz}$ ). Note that MCs 440-470 received strong intensity input. During the first $5 \mathrm{~s}$, the responses of MCs were dense in each sniff cycle, whereas both their firing rates and duration declined as the network dynamics evolved during the learning process. Bottom, GC spiking evolved from random firing to be synchronized dense oscillations, then to sparse oscillations over time. $\boldsymbol{B}$, Sniff-triggered transient responses of MCs (400-500) at different time windows during odor learning. $C$, The MC sparseness as a function of time for the simulation showed in $A$ and $B$, performed with synaptic inhibitory peak conductance $g_{\mathrm{inh}}^{\mathrm{Max}}=3 \mathrm{nS}$ and excitatory peak conductance $g_{\mathrm{ex}}^{\mathrm{Max}}=0.5 \mathrm{nS}$. D, Time evolution of the average excitatory weight $g_{\text {ex }}$ for the MCs receiving strong inputs (red), and for the MCs receiving weak or no inputs (black). $\boldsymbol{E}$, As in $\boldsymbol{D}$ but for the average inhibitory weight. $\boldsymbol{F}$, The average peak inhibitory vs excitatory weight reached in MC receiving strong (red)

clude that there exists an optimal balance $\left(g_{\text {inh }}^{\operatorname{Max}} / g_{\mathrm{ex}}^{\operatorname{Max}}=6.5\right)$, where the network sparseness reaches the highest value (Fig. $8 E$ ), and at which the network response is most decorrelated (Fig. $8 F$ ).

The network's learning process thus leads to more sparseness and more decorrelation. We asked next whether the model with such a learning process could give insight into how these processes contribute to better representation of different odorants.

We assumed $g_{\mathrm{ex}}^{\mathrm{Max}}=0.5 \mathrm{nS}$ and $g_{\mathrm{inh}}^{\mathrm{Max}}=3 \mathrm{nS}$, which are close to the network optimal conditions, and ran the simulations for the olfactory bulb network with each of the 72 odor inputs. We compared the similarity of the network responses to each odor with all 

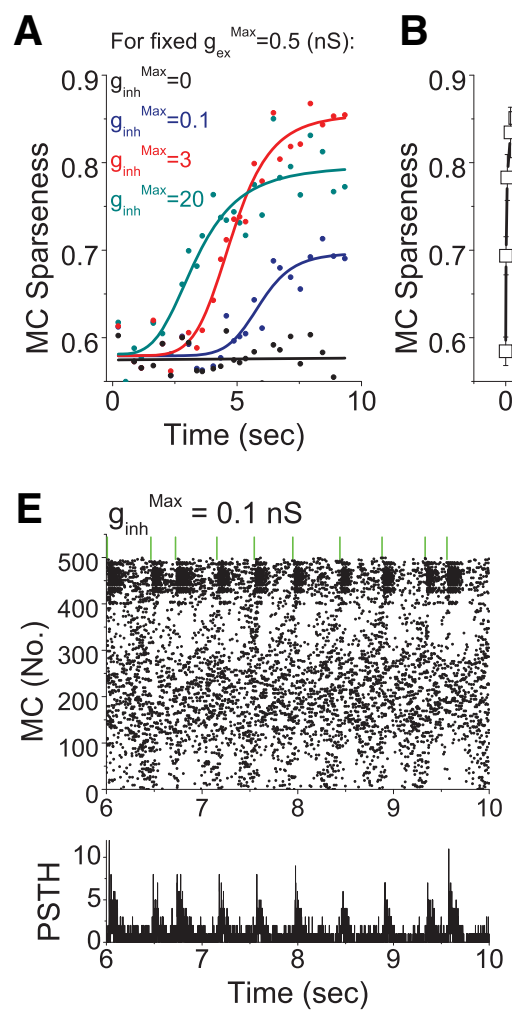

B

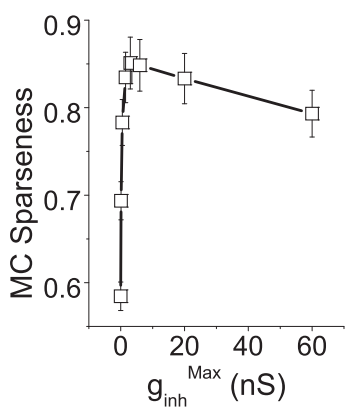

C Sniff-triggered transient

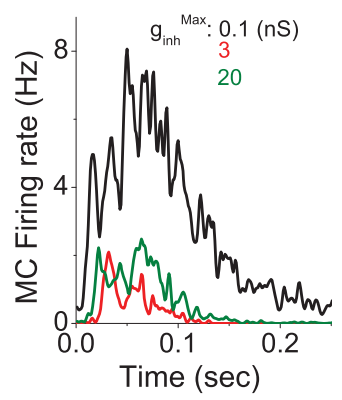

D

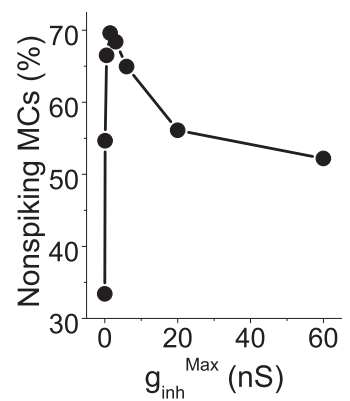

F $g_{\text {inh }}{ }^{\operatorname{Max}}=3 \mathrm{nS}$
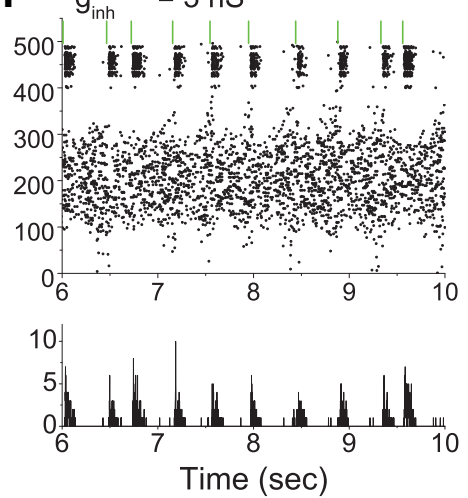
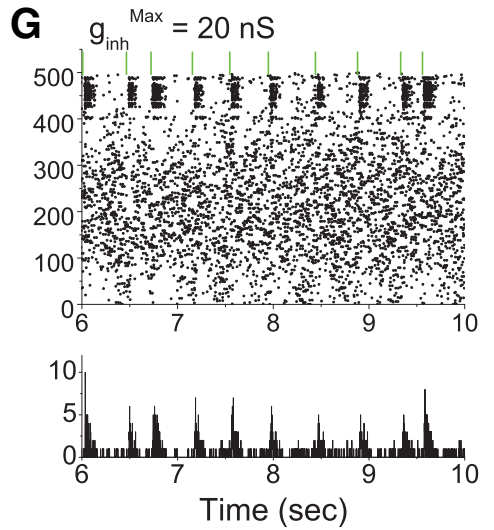

Figure 7. Analysis of the evolution of sparseness in the MC network response. $\boldsymbol{A}$, Sparseness as a function of time for different values of synaptic inhibitory peak conductance $g_{\text {inh }}^{\text {Max }}$ and a fixed synaptic excitatory peak conductance ( $g_{\mathrm{ex}}^{\mathrm{Max}}=0.5 \mathrm{nS}$ ). Note that except for $g_{\mathrm{inh}}^{\mathrm{Max}}=0$, the sparseness of the MC response always self-organizes into a high sparseness level as a function of time. The fitting curves could be described by the classic logarithmic function as follows: $Y=A_{2}+\left(A_{1}-A_{2}\right) /\left(1+\left(\frac{\mathrm{x}}{\mathrm{X}_{0}}\right)^{a}\right)$. $\boldsymbol{B}$, Sparseness level of the MC network response as a function of $g_{\mathrm{inh}}^{\mathrm{Max}}$ for $g_{\mathrm{ex}}^{\mathrm{Max}}=0.5 \mathrm{nS}$. The sparseness level reaches the highest value for $g_{\mathrm{inh}}^{\mathrm{Max}}=3 \mathrm{nS}$. C, Sniff-triggered average MC firing rate after learning (during the 10 th seconds of simulation) for three cases of $g_{\mathrm{inh}}^{\mathrm{Max}}=0.1,3$ and $20 \mathrm{nS}$ respectively. D, Percentage of nonspiking MCs in the network for each sniff cycle after learning. The maximum value is for $g_{\mathrm{inh}}^{\text {Max }}=3 \mathrm{nS}$. $\boldsymbol{E}-\boldsymbol{G}, \mathrm{MC}$ raster plot (top) and PSTH (bottom) during the last $4 \mathrm{~s}$ of simulation for $g_{\mathrm{inh}}^{\operatorname{Max}}=0.1 \mathrm{nS}(\boldsymbol{E}), 3 \mathrm{nS}(\boldsymbol{F})$, and $20 \mathrm{nS}(\boldsymbol{G})$.

the other 71 network responses to other odors. First we defined the correlation coefficient between network responses to odorants $x$ and $y$ during a time window (e.g., first seconds or 10th seconds) as following:

$$
\mathrm{C}_{\mathrm{xy}}=\frac{1}{500} \sum_{i=1}^{500} \operatorname{Corrcoeff}\left\{\mathrm{MC}_{i}[\mathrm{x}(t)], \mathrm{MC}_{i}[\mathrm{y}(t)]\right\}
$$

where $\mathrm{MC}_{i}$ is the $i^{\prime}$ th $\mathrm{MC}$, and Corrcoeff $\left\{\mathrm{MC}_{i}[\mathrm{x}(t)], \mathrm{MC}_{i}[\mathrm{y}(t)]\right\}$ represents the correlation coefficient between the responses of the $i^{\prime}$ th $\mathrm{MC}$ to odorant $x(t)$ and odorant $y(t)$. $C_{x y}$ thus represents the correlation coefficient of the network response to odors $x$ and $y$. For each odor $x$, we calculated the average correlation coefficient with the responses obtained for each of the other 71 odor inputs. We used this as a measure of the similarity between any specific odor-induced response and all the others during the first seconds and 10th seconds of odor presentation. Figure $9 \mathrm{~A}$ summarizes the results by comparing the responses during the first seconds (i.e., before learning) and during the 10th seconds (i.e., after learning). To give a quantitative comparison, we divided the 72 odor network responses into 3 groups: (1) odors activating $>2 \%$ of the MCs with strong inputs (Fig. 9, red symbols), (2) odors activating up to $2 \%$ of the mitral cells with strong inputs (Fig. 9, green symbols), and (3) odors where none of the MCs were activated with strong inputs (Fig. 9, blue symbols). During the first seconds of simulation, the response similarities of the OB network are, in general, much higher than for the 10th seconds. This was especially true for odors containing strong components, which showed an average of $82 \%$ reduction in similarity after learning. This means that the odor learning process is effective in decreasing the correlation between network responses, thus reducing the similarity of odor representation (Fig. $9 B$ ). For odors with $<2 \%$ of highly activated MCs, odor response similarity reduction improved by $44 \%$ (Fig. 9B, green), and there still was an average $18 \%$ improvement for weak odors containing no strong components (Fig. 9B, blue). Either decrease or increase of the value of the inhibitory synaptic peak conductance degrades the independency of odor representation (data not shown), as suggested by a recent experimental study (Nunez-Parra et al., 2013). These results suggest that the balanced excitation/inhibition and response sparseness emerging from the self-organization of the olfactory bulb network during learning is instrumental in disambiguating odor inputs.

To quantify how the learning process in the olfactory bulb network reduces the similarity of odors, we divided the input signals in two groups corresponding to odors with similarity lower or $>0.1$, respectively. Interestingly, simulation results showed that the learning process reduces the similarity of representation of odors with higher similarity (Fig. 9D) similarly or even more than those with lower similarity (Fig. 9C). On average, when the input odor similarity is $\sim 0.05$, the network response similarity is reduced from 0.62 to 0.43 ( $-31 \%$; Fig. 9 C). For inputs with higher similarity (Fig. 9D), the average similarity of the network response is reduced from 0.55 to $0.36(-35 \%)$. Lateral inhibition and response sparseness enhance the ability of the olfactory bulb to form an independent representation of input odors. This action of the network is seen most clearly in separating similar odorants as the strength of input increases (Fig. 9B).

\section{Discussion}

Using a scaled up mitral-granule cell network model, we propose a novel mechanism in which the relative balance between excitation and inhibition in dendrodendritic synapses modulates the 
A

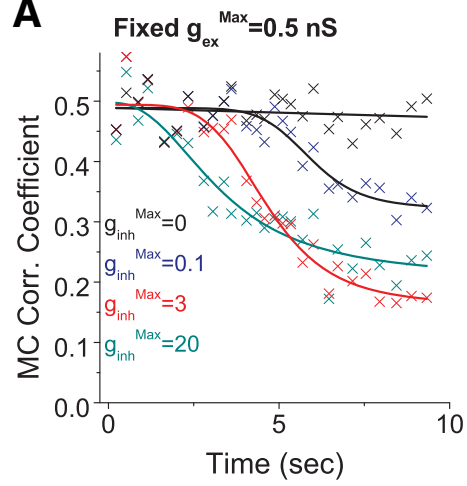

D

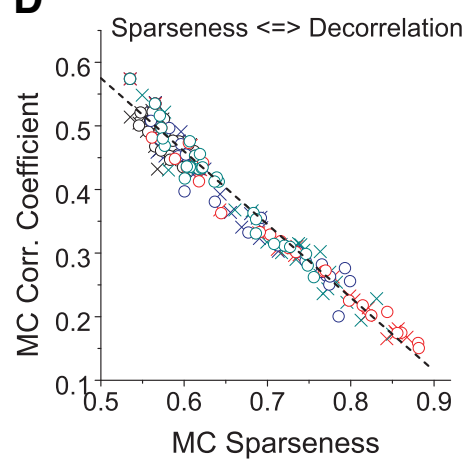

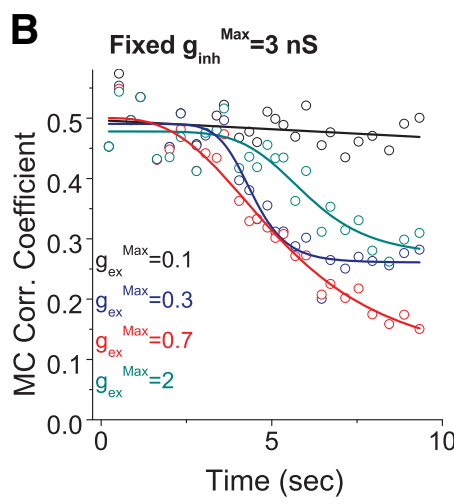

E

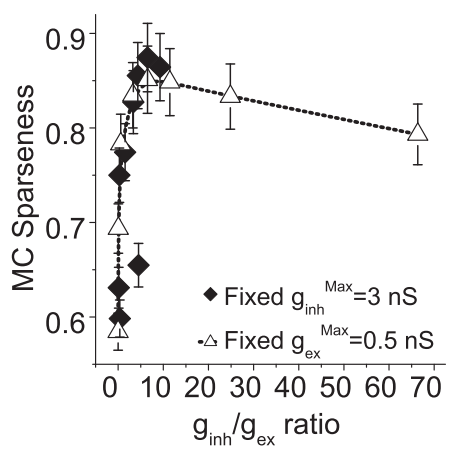

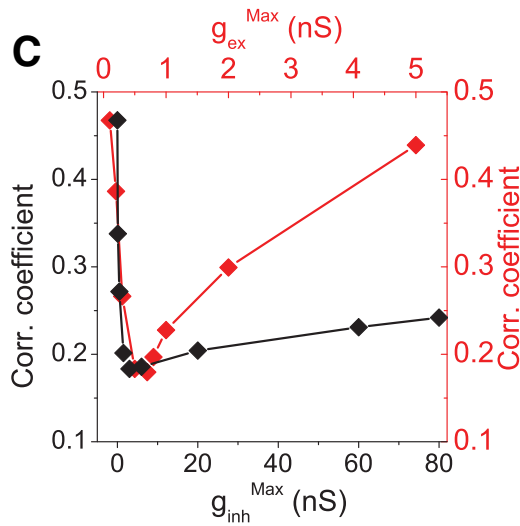

F

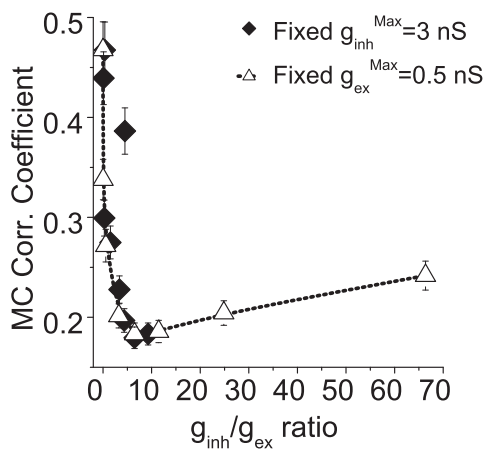

Figure 8. Sparseness as a function of the ratio between the dendrodendritic synaptic actions. $\boldsymbol{A}$, The averaged correlation coefficient of the $M C$ network response as a function of time for different values of $g_{\mathrm{inh}}^{\mathrm{Max}}$ and a fixed $g_{\mathrm{ex}}^{\mathrm{Max}}=0.5 \mathrm{nS}$. Note that except for $g_{\mathrm{inh}}^{\mathrm{Max}}=0$, the MC network correlation level always declines as a function of time. The curves are described by the classic logarithmic function (Fig. 6, legend). B, The average correlation coefficient of the MC network response as a function of time for different values of $g_{\mathrm{ex}}^{\text {Max }}$ for a fixed $g_{\mathrm{inh}}^{\text {Max }}=3 \mathrm{nS}$. $\boldsymbol{C}$, The MC network correlation level as a function of $g_{\mathrm{inh}}^{\mathrm{Max}}$ (black) and $g_{\mathrm{ex}}^{\operatorname{Max}}(\mathrm{red})$. There exists an optimal $g_{\mathrm{inh}}^{\mathrm{Max}}$, as well as an optimal $g_{\mathrm{ex}}^{\text {Max }}$ for which the network correlation level reaches the lowest level. D, The MC network correlation level as a function of network sparseness level. $\boldsymbol{E}$, The MC network sparseness level as a function of reciprocal inhibitory weight to excitation weight ratio $g_{\text {inh }} / g_{\text {ex }}$ for the cases of different $g_{\text {inh }}^{\text {Max }}$ with a fixed $g_{\mathrm{ex}}^{\mathrm{Max}}=0.5 \mathrm{nS}$ and different $g_{\mathrm{ex}}^{\mathrm{Max}}$ with a fixed $g_{\mathrm{inh}}^{\mathrm{Max}}=0.3 \mathrm{nS}$. The network sparseness level is modulated by the $g_{\text {inh }} / g_{\mathrm{ex}}$ ratio. $\boldsymbol{F}$, The MC network correlation level as a function of reciprocal inhibitory weight to excitation weight ratio $g_{\mathrm{inh}} / g_{\mathrm{ex}}$ for the cases of different $g_{\mathrm{inh}}^{\mathrm{Max}}$ with a fixed $g_{\mathrm{ex}}^{\mathrm{Max}}=0.5 \mathrm{nS}$ and different $g_{\mathrm{ex}}^{\mathrm{Max}}$ with a fixed $g_{\mathrm{inh}}^{\mathrm{Max}}=0.3 \mathrm{nS}$. The network correlation level is modulated by the $g_{\text {inh }} / g_{\text {ex }}$ ratio.

sparse representation of input odors in the olfactory bulb. Spiking responses of the most active mitral cells are governed by balanced excitation and inhibition in the dendrodendritic synapses that evolves during the odor learning process. Spiking responses of surrounding, weakly activated, MCs are modulated by lateral inhibition generated by the unbalanced inhibition from dendrodendritic synapses along the mitral cell lateral dendrites. These mechanisms act to enhance representation of different odors by the whole olfactory bulb network.

We discuss how each of these properties arises from the functional architecture of the network.

\section{Balanced excitation and inhibition in dendrodendritic synapses}

The balance between excitation and inhibition has been suggested as a critical factor in the functioning of cortical structures (Shu et al., 2003; Haider et al., 2006). We have characterized its function in the olfactory bulb through the dendrodendritic synaptic circuit. Mitral cells that receive suprathreshold excitatory input from their glomerulus also elicit feedback inhibition from granule cells along their lateral dendrite. Our model is consistent with the results from Shen et al. (1999), showing that this can also occur with weak glomerular activation, when action potentials initiate in the axon in the usual manner; with moderate to strong activation, action potentials can be initiated in the distal apical dendrite, with propagation to the soma and initial axon segment (Shen et al., 1999). In either case, action potentials back- propagate into the lateral dendrites in the external plexiform layer (Xiong and Chen, 2002).

These properties arise naturally in our model. Strong responses of MCs (characterized as MC I) give rise to backpropagating action potentials in their lateral dendrites, with strong activation of granule cells through the excitatory member of the dendrodendritic synapse, and strong lateral inhibition through the inhibitory dendrodendritic member of the pair $(\mathrm{Yu}$ et al., 2013). When the action potential propagates down the lateral dendrite, it activates excitatory synapses onto dendritic spines of many individual granule cells; they in turn feedback inhibition that converges onto that dendrite (as well as delivering lateral inhibition onto other mitral cell dendrites). The reciprocal nature of the dendrodendritic synapses thus favors strong inhibition, even when it is activated by strong excitatory drive from activated glomeruli. We hypothesize that the significance of this balance is to ensure that strong to very strong activation of the apical dendrites is balanced by feedback inhibition on the lateral dendrites, to oppose overexcitability of the MC and its output in the axonal initial segment. Blocking GABAergic inhibition induces seizure activity by mitral cells even under resting conditions (Nowycky et al., 1981).

Lateral inhibition from unbalanced excitation and inhibition in dendrodendritic synapses

Strong lateral inhibition occurs after the granule cells begin to generate inhibitory signals in response to inputs from MC I. This 

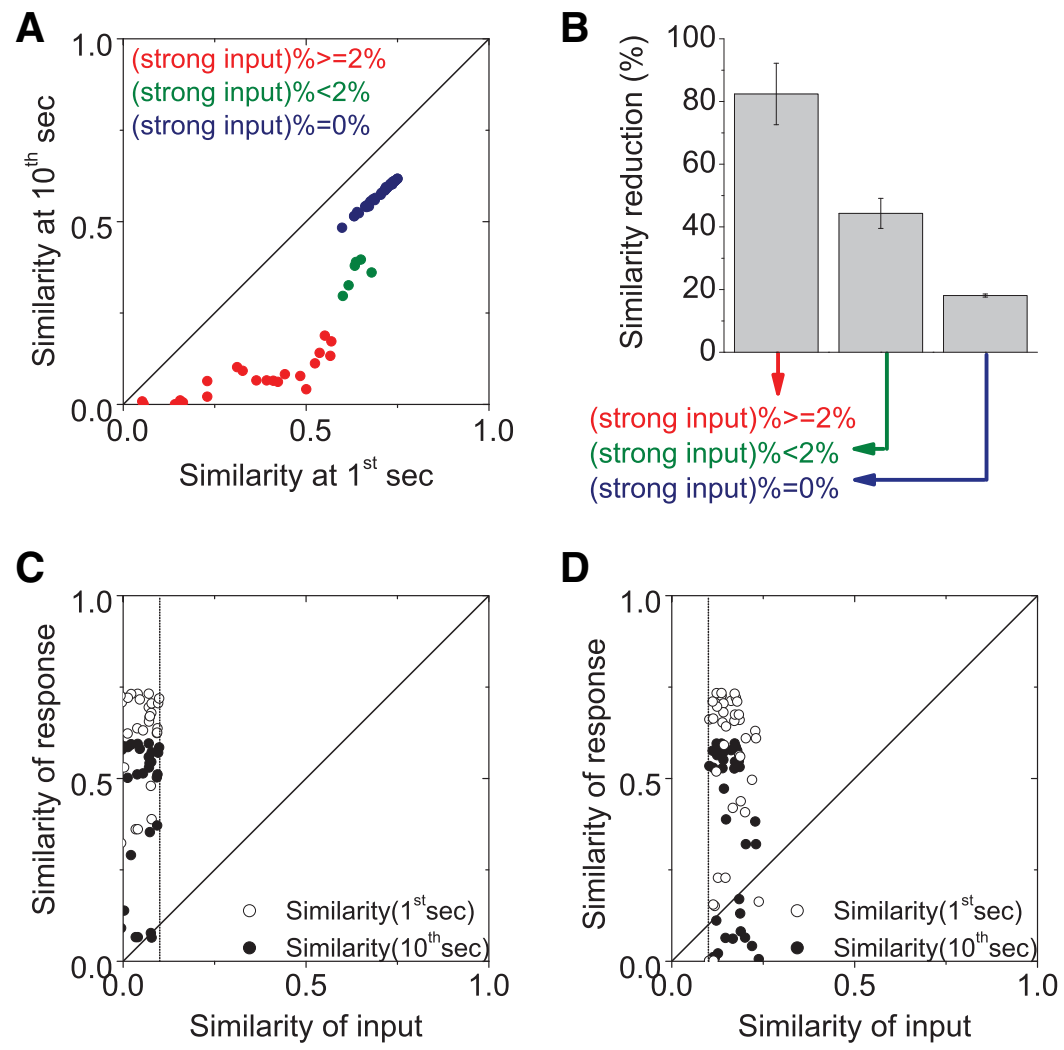

Figure 9. Similarity reduction in odor representation promoted by network learning. $\boldsymbol{A}$, The similarity of the MC network responses to different odor inputs can be quantified by calculating the average value of the correlation coefficients of the responses to each odor input with the other 71 odor inputs. The 72 odor network responses were divided into three groups: odors with $>2 \%$ of the mitral cells activated with a strong input (red), odors with $<2 \%$ of MCs activated by a strong input (green), and odors with no strong inputs (blue). $\boldsymbol{B}$, Plots showing the reduction in similarity of network response after the learning process for the three groups. $\boldsymbol{C}, \boldsymbol{D}$, Similarity of response for odors with a value of input similarity lower $(\boldsymbol{C})$ or higher $(\boldsymbol{D})$ than 0.1 .

leads to an unbalanced excitation and inhibition (inhibition dominated), with a very high ratio, delivered by dendrodendritic synapses on the dendrites of surrounding MCs with weak input (characterized as MC II cells).

Lateral inhibition in the olfactory bulb is the counterpart of the lateral inhibition that is widely observed in the early pathways of vision, audition, and somatosensation, and is suggested to be engaged in shaping sensory discrimination and enhancing coding accuracy. It was initially proposed in combined experimental and computational studies(Rall et al., 1966; Rall and Shepherd, 1968) and has been supported by numerous subsequent experiments (Yokoi et al., 1995) and computational or conceptual modeling studies (Yokoi et al., 1995; Urban, 2002; Koulakov and Rinberg, 2011; Yu et al., 2013).

These studies have supported the hypothesis that an essential function of lateral inhibition in the olfactory bulb is to enhance odor representation between different odors, but its investigation at the network level could not have been directly verified, in a model or experimentally. Our model gave the opportunity to test this mechanism under more realistic network configurations, because it directly used experimentally determined patterns of input for different odors to the different glomeruli. We tested the patterns of mitral cell firing in response to both structurally similar odor molecules and structurally different molecules (Fig. 5). Responses to different odor molecules showed different responses in MCs, including those that did not receive a direct input. This suggests that the network is able to actively enhance odor representation of different odors, even if they are structur- ally similar. A detailed study of the relation between odor molecule structure, model circuit responses, and perceptual qualities will be performed in the future.

\section{Sparseness, decorrelation, and odor representation similarity}

Recent studies (Rinberg et al., 2006; Davison and Katz, 2007; Franco et al., 2007; Poo and Isaacson, 2009; Dhawale et al., 2010; Khan et al., 2010; Koulakov and Rinberg, 2011; Giridhar et al., 2011; Kato et al., 2012; Yu et al., 2013) have focused on two emergent properties of olfactory bulb circuit responses to odors: sparsening and decorrelation. Our model results suggest that the circuit based on dendrodendritic synapses is deeply involved in both properties.

Sparsening appears as the change, from continuous high-frequency spike firing to a transient response during each sniff, in mitral cell responses to strong glomerular input. Both the balanced and unbalanced excitation/inhibition (inhibition dominated) contribute to its development.

We have also examined the dependence of response decorrelation with sparseness level. As proposed by sparse coding theory (Olshausen and Field, 1996; Vinje and Gallant, 2000; Koulakov and Rinberg, 2011) and experimental tests (Vinje and Gallant, 2000; Davison and Katz, 2007; Poo and Isaacson, 2009; Dhawale et al., 2010; Wolfe et al., 2010), higher sparseness is associated with more decorrelated responses. This property is shown by the mitral-granule cell network model (Fig. $8 D$ ). The decorrelated responses suggest a reduction in the redundancy of the coding scheme, resulting in a sparse code (Olshausen and Field, 1996). By increasing the decorrelation of network response to a given odor during the learning process, the capacity for odor representation is greatly increased (Fig. 9). As noted above, this included representation of monomolecular odorants with similar, as well as different, chemical structures.

An important finding of our model is that the highest level of sparseness and decorrelation requires an optimal match of excitation and inhibition that needs to be preserved to allow the network to perform effectively. Any physiological or pathological alteration in the excitation/inhibition balance will cause a degradation of odor recognition capabilities.

In addition, the learning process can affect the way in which the network learns a new odorant (as in any self-organizing network). The overall effect will depend on the structure of the odors that are presented to the network. Orthogonal odors (i.e., with inputs that do not overlap) would not be expected to be affected by training history, whereas more overlapping ones will be. An exploration of this issue is outside the scope of the paper. A somewhat similar problem (i.e., the effect of previous training on the storage of new memories) was discussed in a recent paper for a CA1 network (Bianchi et al., 2014). For olfaction, the specific sequence of odors with which the network is trained can result in somewhat different activity for specific mitral cells or glomeruli. At a behavioral level, this may explain individual differences in 
odor perception/recognition. However, the general mechanism we discuss in this paper would still be relevant independently of the training history.

In summary, we have analyzed the operation of a physiologically realistic model of the olfactory bulb mitral-granule cell microcircuit without any predesigned features for special functions or properties. The model suggests a process through which two fundamental computational mechanisms can emerge in the olfactory bulb network to facilitate independent odor representation: (1) a balanced excitation/inhibition mechanism in the dendrodendritic synapses of cells with strong inputs that can account for the generation of a sparse representation of odors, and (2) an unbalanced excitation/inhibition (inhibition dominated) mechanism in the dendrodendritic synapses surrounding highly active mitral cells that can account for the generation of lateral inhibition. Because of the tight and fast control exerted by these processes on the mitral cell output, we hypothesize that these mechanisms form the basis for independent odor representation by the mitral-granule cell network at short time scales, with additional intrinsic and extrinsic factors acting to fine tune representation of more complex inputs at longer time scales.

\section{References}

Abraham NM, Egger V, Shimshek DR, Renden R, Fukunaga I, Sprengel R, Seeburg PH, Klugmann M, Margrie TW, Schaefer AT, Kuner T (2010) Synaptic inhibition in the olfactory bulb accelerates odor discrimination in mice. Neuron 65:399-411. CrossRef Medline

Antón PS, Granger R, Lynch G (1993) Simulated dendritic spines influence reciprocal synaptic strengths and lateral inhibition in the olfactory-bulb. Brain Res 628:157-165. CrossRef Medline

Arevian AC, Kapoor V, Urban NN (2008) Activity-dependent gating of lateral inhibition in the mouse olfactory bulb. Nat Neurosci 11:80-87. CrossRef Medline

Bianchi D, De Michele P, Marchetti C, Tirozzi B, Cuomo S, Marie H, Migliore M (2014) Effects of increasing CREB-dependent transcription on the storage and recall processes in a hippocampal CA1 microcircuit. Hippocampus 24:165-177. CrossRef Medline

Bienenstock EL, Cooper LN, Munro PW (1982) Theory for the development of neuron selectivity: orientation specificity and binocular interaction in visual cortex. J Neurosci 2:32-48. Medline

Bischofberger J, Jonas P (1997) Action potential propagation into the presynaptic dendrites of rat mitral cells. J Physiol 504:359-365. CrossRef Medline

Carey RM, Wachowiak M (2011) Effect of sniffing on the temporal structure of mitral/tufted cell output from the olfactory bulb. J Neurosci 31: 10615-10626. CrossRef Medline

Cleland TA, Linster C (2012) On-center/inhibitory-surround decorrelation via intraglomerular inhibition in the olfactory bulb glomerular layer. Front Integr Neurosci 6:5. CrossRef Medline

Davison A, Feng JF, Brown D (1999) Structure of lateral inhibition in an olfactory bulb model. In: Foundations and tools for neural modeling (Mira J, Sánchez-Andrés JV, eds), pp 189-196. Berlin: Springer. CrossRef

Davison IG, Katz LC (2007) Sparse and selective odor coding by mitral/ tufted neurons in the main olfactory bulb. J Neurosci 27:2091-2101. CrossRef Medline

Debarbieux F, Audinat E, Charpak S (2003) Action potential propagation in dendrites of rat mitral cells in vivo. J Neurosci 23: 5553-5560. Medline

Dhawale AK, Hagiwara A, Bhalla US, Murthy VN, Albeanu DF (2010) Nonredundant odor coding by sister mitral cells revealed by light addressable glomeruli in the mouse. Nat Neurosci 13:1404-1412. CrossRef Medline

Egger V, Svoboda K, Mainen ZF (2003) Mechanisms of lateral inhibition in the olfactory bulb: efficiency and modulation of spike-evoked calcium influx into granule cells. J Neurosci 23:7551-7558. Medline

Fantana AL, Soucy ER, Meister M (2008) Rat olfactory bulb mitral cells receive sparse glomerular inputs. Neuron 59:802-814. CrossRef Medline

Finelli LA, Haney S, Bazhenov M, Stopfer M, Sejnowski TJ (2008) Synaptic learning rules and sparse coding in a model sensory system. PLoS Comput Biol 4:e1000062. CrossRef Medline

Franco L, Rolls ET, Aggelopoulos NC, Jerez JM (2007) Neuronal selectivity, population sparseness, and ergodicity in the inferior temporal visual cortex. Biol Cybern 96:547-560. CrossRef Medline

Fuchs JL, Brown PB (1984) 2-point discriminability: relation to properties of the somatosensory system. Somatosens Res 2:163-169. Medline

Giridhar S, Doiron B, Urban NN (2011) Timescale-dependent shaping of correlation by olfactory bulb lateral inhibition. Proc Natl Acad Sci U S A 108:5843-5848. CrossRef Medline

Haider B, Duque A, Hasenstaub AR, McCormick DA (2006) Neocortical network activity in vivo is generated through a dynamic balance of excitation and inhibition. J Neurosci 26:4535-4545. CrossRef Medline

Haykin S (1994) Neural networks: a comprehensive foundation. New York: Macmillan.

Hines M, Carnevale NT (1997) The NEURON simulation environment. Neural Comp 9:1179-1209. Medline

Hines ML, Carnevale NT (2001) NEURON: a tool for neuroscientists. Neuroscientist 7:123-135. CrossRef Medline

Isaacson JS, Vitten H (2003) GABA(B) receptors inhibit dendrodendritic transmission in the rat olfactory bulb. J Neurosci 23:2032-2039. Medline

Kato HK, Chu MW, Isaacson JS, Komiyama T (2012) Dynamic sensory representations in the olfactory bulb: modulation by wakefulness and experience. Neuron 76:962-975. CrossRef Medline

Khan AG, Parthasarathy K, Bhalla US (2010) Odor representations in the mammalian olfactory bulb. Wiley Interdiscip Rev Syst Biol Med 2:603611. CrossRef Medline

Koulakov AA, Rinberg D (2011) Sparse incomplete representations: a potential role of olfactory granule cells. Neuron 72:124-136. CrossRef Medline

Kuffler SW (1953) Discharge patterns and functional organization of mammalian retina. J Neurophysiol 16:37-68. Medline

Lagier S, Panzanelli P, Russo RE, Nissant A, Bathellier B, Sassoè-Pognetto M, Fritschy JM, Lledo PM (2007) GABAergic inhibition at dendrodendritic synapses tunes gamma oscillations in the olfactory bulb. Proc Natl Acad Sci U S A 104:7259-7264. CrossRef Medline

Lin DY, Shea SD, Katz LC (2006) Representation of natural stimuli in the rodent main olfactory bulb. Neuron 50:937-949. CrossRef Medline

Mandairon N, Linster C (2009) Odor perception and olfactory bulb plasticity in adult mammals. J Neurophysiol 101: 2204-2209. CrossRef Medline

Margrie TW, Sakmann B, Urban NN (2001) Action potential propagation in mitral cell lateral dendrites is decremental and controls recurrent and lateral inhibition in the mammalian olfactory bulb. Proc Natl Acad Sci U S A 98:319-324. CrossRef Medline

Matsumoto H, Kashiwadani H, Nagao H, Aiba A, Mori K (2009) Odorinduced persistent discharge of mitral cells in the mouse olfactory bulb. J Neurophysiol 101:1890-1900. CrossRef Medline

Migliore M, Shepherd GM (2008) Dendritic action potentials connect distributed dendrodendritic microcircuits. J Comput Neurosci 24:207-221. CrossRef Medline

Migliore M, Hoffman DA, Magee JC, Johnston D (1999) Role of an A-type $\mathrm{K}+$ conductance in the back-propagation of action potentials in the dendrites of hippocampal pyramidal neurons. J Comput Neurosci 7:5-15. CrossRef Medline

Migliore M, Inzirillo C, Shepherd GM (2007) Learning mechanism for column formation in the olfactory bulb. Front Integr Neurosci 1:12. CrossRef Medline

Migliore M, Hines ML, McTavish TS, Shepherd GM (2010) Functional roles of distributed synaptic clusters in the mitral-granule cell network of the olfactory bulb. Front Integr Neurosci 4:122. CrossRef Medline

Mori K, Takahashi YK, Igarashi KM, Yamaguchi M (2006) Maps of odorant molecular features in the mammalian olfactory bulb. Physiol Rev 86:409_ 433. CrossRef Medline

Murphy GJ, Darcy DP, Isaacson JS (2005) Intraglomerular inhibition: signaling mechanisms of an olfactory microcircuit. Nat Neurosci 8:354-364. CrossRef Medline

Nowycky MC, Mori K, Shepherd GM (1981) Blockade of synaptic inhibition reveals long-lasting synaptic excitation in isolated turtle olfactory bulb. J Neurophysiol 46:649-658. Medline

Nunez-Parra A, Maurer RK, Krahe K, Smith RS, Araneda RC (2013) Disruption of centrifugal inhibition to olfactory bulb granule cells impairs olfactory discrimination. Proc Natl Acad Sci U S A 110:14777-14782. CrossRef Medline

Olsen SR, Wilson RI (2008) Lateral presynaptic inhibition mediates gain control in an olfactory circuit. Nature 452:956-960. CrossRef Medline 
Olshausen BA, Field DJ (1996) Emergence of simple-cell receptive field properties by learning a sparse code for natural images. Nature 381:607609. CrossRef Medline

Oswald AMM, Schiff ML, Reyes AD (2006) Synaptic mechanisms underlying auditory processing. Curr Opin Neurobiol 16:371-376. CrossRef Medline

Otsuka T, Kawaguchi Y (2009) Cortical inhibitory cell types differentially form intralaminar and interlaminar subnetworks with excitatory neurons. J Neurosci 29: 10533-10540 CrossRef Medline

Poo C, Isaacson JS (2009) Odor representations in olfactory cortex: sparse coding, global inhibition, and oscillations. Neuron 62:850-861. CrossRef Medline

Rall W, Shepherd GM (1968) Theoretical reconstruction of field potentials and dendrodendritic synaptic interactions in olfactory bulb. J Neurophysiol 31:884-915. Medline

Rall W, Shepherd GM, Reese TS, Brightman MW (1966) Dendrodendritic synaptic pathway for inhibition in the olfactory bulb. Exp Neurol 14:4456. CrossRef Medline

Rinberg D, Koulakov A, Gelperin A (2006) Sparse odor coding in awake behaving mice. J Neurosci 26:8857-8865. CrossRef Medline

Shen GY, Chen WR, Midtgaard J, Shepherd GM, Hines ML (1999) Computational analysis of action potential initiation in mitral cell soma and dendrites based on dual patch recordings. J Neurophysiol 82:3006-3020. Medline

Shepherd GM, Brayton RK (1979) Computer-simulation of a dendrodendritic synaptic circuit for self-inhibition and lateral-inhibition in the olfactory-bulb. Brain Res 175:377-382. CrossRef Medline

Shepherd GM, Chen WR, Willhite D, Migliore M, Greer CA (2007) The olfactory granule cell: from classical enigma to central role in olfactory processing. Brain Res Rev 55:373-382. CrossRef Medline

Shu Y, Hasenstaub A, McCormick DA (2003) Turning on and off recurrent balanced cortical activity. Nature 423:288-293. CrossRef Medline

Shusterman R, Smear MC, Koulakov AA, Rinberg D (2011) Precise olfactory responses tile the sniff cycle. Nat Neurosci 14:1039-1044. CrossRef Medline

Smear M, Shusterman R, O'Connor R, Bozza T, Rinberg D (2011) Perception of sniff phase in mouse olfaction. Nature 479:397-400. CrossRef Medline
Stanton PK (1996) LTD, LTP, and the sliding threshold for long-term synaptic plasticity. Hippocampus 6:35-42. CrossRef Medline

Stewart WB, Kauer JS, Shepherd GM (1979) Functional organization of rat olfactory bulb analysed by the 2-deoxyglucose method. J Comp Neurol 185:715-734. CrossRef Medline

Tomita T (1958) Mechanism of lateral inhibition in eye of limulus. J Neurophysiol 21:419-429. Medline

Urban NN (2002) Lateral inhibition in the olfactory bulb and in olfaction. Physiol Behav 77:607-612. CrossRef Medline

Urban NN, Margrie TW, Sakmann B (2000) Dendritic propagation and lateral inhibition in mitral cells of the rodent main olfactory bulb. Eur J Neurosci 12:365.

Valley MT, Firestein S (2008) A lateral look at olfactory bulb lateral inhibition. Neuron 59:682-684. CrossRef Medline

Vinje WE, Gallant JL (2000) Sparse coding and decorrelation in primary visual cortex during natural vision. Science 287:1273-1276. CrossRef Medline

Wachowiak M (2011) All in a sniff: olfaction as a model for active sensing. Neuron 71:962-973. CrossRef Medline

Wang XJ, Buzsáki G (1996) Gamma oscillation by synaptic inhibition in a hippocampal interneuronal network model. J Neurosci 16:6402-6413. Medline

Whitesell JD, Sorensen KA, Jarvie BC, Hentges ST, Schoppa NE (2013) Interglomerular lateral inhibition targeted on external tufted cells in the olfactory bulb. J Neurosci 33:1552-1563. CrossRef Medline

Willhite DC, Nguyen KT, Masurkar AV, Greer CA, Shepherd GM, Chen WR (2006) Viral tracing identifies distributed columnar organization in the olfactory bulb. Proc Nat Acad Sci U S A 103:12592-12597. CrossRef Medline

Wolfe J, Houweling AR, Brecht M (2010) Sparse and powerful cortical spikes. Curr Opin Neurobiol 20:306-312. CrossRef Medline

Xiong W, Chen WR (2002) Dynamic gating of spike propagation in the mitral cell lateral dendrites. Neuron 34:115-126. CrossRef Medline

Yokoi M, Mori K, Nakanishi S (1995) Refinement of odor molecule tuning by dendrodendritic synaptic inhibition in the olfactory bulb. Proc Natl Acad Sci U S A 92:3371-3375. CrossRef Medline

Yu Y, McTavish TS, Hines ML, Shepherd GM, Valenti C, Migliore M (2013) Sparse distributed representation of odors in a large-scale olfactory bulb circuit. PLoS Comput Biol 9:e1003014. CrossRef Medline 